\title{
High-strain deformation of conglomerates: numerical modelling, strain analysis, and an example from the Wutai Mountains, North China Craton
}

Hao Ran ${ }^{\mathrm{a}, \mathrm{b}}$, Paul D. Bons ${ }^{\mathrm{a},}$, Genhou Wang ${ }^{\mathrm{b}}$, Florian Steinbach ${ }^{\mathrm{a}}$, Melanie Finch ${ }^{\mathrm{a}}$, Albert Griera ${ }^{\mathrm{c}}$, Enrique Gomez-Rivas ${ }^{\mathrm{d}, \mathrm{e}}$, Maria-Gema Llorens ${ }^{\mathrm{a}}$, Shuming Ran ${ }^{\mathrm{f}}$, Xiao Liang ${ }^{\mathrm{b}}$ and Jie Zhou ${ }^{\mathrm{g}}$

a Department of Geosciences, Eberhard Karls University Tübingen, Tübingen 72074, Germany $b$ School of Earth Sciences and Resources, China University of Geosciences, Beijing 100083, China c Departament de Geologia, Universitat Autònoma de Barcelona, Bellaterra (Cerdanyola del V.) 08193, Spain d Departament de Mineralogia, Petrologia i Geologia Aplicada, Universitat de Barcelona, Barcelona 08028, Spain e School of Geosciences, University of Aberdeen, AB24 3UE Aberdeen, United Kingdom $f$ Tianjin Center, China Geological Survey, Tianjin 300170, China $g$ Key Laboratory of Submarine Geosciences and Prospecting Techniques, Ministry of Education; College of Marine Geosciences, Ocean University of China, Qingdao 266100, China

*Corresponding author: Department of Geosciences, Eberhard Karls University Tübingen, Wilhelmstr. 56, 72074 Tübingen, Germany. Tel.: +49- 7071-2976469.paul.bons@uni-tuebingen.de

This article is published in the Journal of Structural Geology (2018), 114, 222-234. DOI: 10.1016/j.jsg.2018.06.018. This is an author's version of the manuscript. To download the final copy-edited version please visit:

https://www.sciencedirect.com/science/article/pii/S0191814118301846 
High-strain deformation of conglomerates: numerical modelling, strain analysis, and an example from the Wutai Mountains, North China Craton

Hao Ran a, b, Paul D. Bons ${ }^{a,}{ }^{*}$, Genhou Wang ${ }^{b}$, Florian Steinbach ${ }^{a}$, Melanie Finch $^{\text {a, }}$ Albert Griera c ${ }^{\text {, Enrique Gomez-Rivas d,e, Maria-Gema Llorens }}{ }^{\text {a }}$, Shuming Ran ${ }^{\mathrm{f}}$, Xiao Liang ${ }^{\mathrm{b}}$, Jie Zhou ${ }^{\mathrm{g}}$

a Department of Geosciences, Eberhard Karls University Tübingen, Tübingen 72074, Germany

b School of Earth Sciences and Resources, China University of Geosciences, Beijing 100083, China

c Departament de Geologia, Universitat Autònoma de Barcelona, Bellaterra (Cerdanyola del V.) 08193, Spain

d Departament de Mineralogia, Petrologia i Geologia Aplicada, Universitat de Barcelona, Barcelona 08028, Spain

e School of Geosciences, University of Aberdeen, AB24 3UE Aberdeen, United Kingdom

f Tianjin Center, China Geological Survey, Tianjin 300170, China

9 Key Laboratory of Submarine Geosciences and Prospecting Techniques, Ministry of Education; College of Marine Geosciences, Ocean University of China, Qingdao 266100, China

${ }^{*}$ Corresponding author: Department of Geosciences, Eberhard Karls 
University Tübingen, Wilhelmstr. 56, 72074 Tübingen, Germany. Tel.: +497071-2976469.ppaul.bons@uni-tuebingen.de

\section{Keywords}

Conglomerates, numerical modelling, strain analysis, North China Craton

\section{Abstract}

Conglomerates have been widely used to investigate deformation history and rheology, strain, vorticity and viscosity. Previous studies reveal that several factors, such as pebble shapes and concentrations, as well as material properties, affect conglomerate deformation. However, how pebble concentration and interaction between pebbles affect deformation is not understood very well. e use the $2 \mathrm{D}$ numerical modelling platform ELLE coupled to the full field crystal visco-plasticity code (VPFFT) to simulate the deformation of conglomerates with various viscosity contrasts between pebbles and matrix and different pebble concentrations, with both linear $(n=1)$ and power-law $(n=3)$ viscous rheologies, under simple shear conditions up to a shear strain of ten. Pebbles can behave effectively passive, deformable or effectively rigid. An increase in concentrations/viscosity contrasts enhances pebble deformation, but reduces their rotation. A mean $R_{f}-\phi$ plot is proposed to gain an estimate of pebble deformation behaviour and the amount of strain. 
Clusters formed by the association of several closely spaced rigid or deformable pebbles can behave as single objects. Rigid clusters rotate and survive for only short strain increments, whereas the more stable deformable ones keep on elongating with minor rotation. We provide a natural example of deformed conglomerates from the Wutai Mountains, North China Craton. Using the mean $R_{f}-\phi$ plot, a simple shear strain of $\sim 6$ could be determined. The viscosity contrast between BIFs pebbles and schist matrix is estimated at about $5-8$ for a linear rheology ( $n=1)$ or $2-5$ if a power-law rheology with $n=3$ is assumed.

\section{Introduction}

Conglomerates have received particular attention in structural geology for studies on strain analysis, deformation process, rheology and tectonic evolution (e.g., Flinn, 1956; Ramsay, 1967; Dunnet, 1969; Fry, 1979; Lisle et al., 1983; Yin et al., 1999; Treagus and Treagus, 2002; Passchier and Trouw, 2005; Czeck et al., 2009). Deformed conglomerates are classical indicators of finite strain, stress orientation, vorticity, and viscosity contrast between pebbles and their matrix (e.g., Ramsay, 1967; Lisle et al., 1985; Freeman and Lisle, 1987; Czeck and Hudleston, 2003). Conglomerates are polyphase rocks formed by pebbles (inclusions) embedded in a matrix that is usually assumed weaker than these (e.g., Gay, 1968; Fletcher, 2004; Jiang, 2007a,b, 2013; 
Marques et al., 2014). A range of rock and analogue deformation experiments, analytical models, as well as numerical simulations have been applied to study the viscous deformation of single or multiple inclusion-matrix systems aiming to quantify their behaviour (e.g., Jeffery, 1922; Rosenberg, 2001; Treagus, 2002; Treagus and Treagus, 2002; Mancktelow, 2002, 2011; Mandal et al., 2003, 2005; Takeda and Griera, 2006; Jiang, 2007a,b, 2013; Jiang and Bentley, 2012; Johnson et al., 2009a,b; Griera et al., 2011, 2013; Dabrowski et al., 2012; Räss et al., 2016; Ran et al., in review). These studies reveal that there are several key factors that control their deformation behaviour: (1) the initial shape of inclusion(s) (Lisle, 1979; Treagus, 2002; Treagus and Lan, 2004), (2) the material properties, in particular the viscosity contrast between inclusion and matrix (Treagus and Treagus, 2001; Mandal et al., 2003; Vitale and Mazzoli, 2005; Takeda and Griera, 2006; Griera et al., 2013), the matrix anisotropy (Treagus, 2003; Fletcher, 2004; Griera et al., 2011, 2013; Qu et al., 2016) and the linear or power-law rheology (Mancktelow, 2002, 2011; Jiang, 2013; Qu et al., 2016), (3) the behaviour of the interface between inclusion and matrix (Marques and Bose, 2004; Johnson et al., 2009b), and (4) the distribution of inclusions (Treagus, 2002; Takeda and Griera, 2006) and the interaction between them (Ildefonse et al., 1992a,b; Tikoff and Teyssier, 1994; Marques and Bose, 2004; Mandal et al., 2005; Jessell et al., 2009; Mancktelow, 2011). 
Pebbles in a ductile viscous conglomerate can behave as passive, deformable or rigid inclusions, depending on the viscosity contrast between pebbles and matrix. The first analytical solutions, proposed by Eshelby (1957) and Gay (1968) and further developed by Bilby et al. (1975), Bilby and Kolbuszewski (1977) and Treagus and Treagus (2001), indicate that inclusions in linear viscous systems deformed in pure shear behave passively (i.e., their deformation rate approximately equals that of the matrix) when the viscosity ratio $(R \eta)$ between inclusion and matrix is less than two. Initially circular inclusions remain effectively rigid (i.e., inclusions only undergo very minor deformation) when $R \eta$ is larger than ca. 20 to 50 . In between these two end members we define "deformable inclusions" as those that deform significantly, but distinctly less than their surrounding matrix. Pulsating behaviour, with cyclical rotation of inclusions and changes in their ellipticity, can occur in noncoaxial shearing at moderate $R \eta$ (Bilby and Kolbuszewski, 1977). Based on analogue experiments, Piazolo and Passchier (2002) estimated the transitions between rigid, pulsating and passive behaviour in simple shear at $R \eta=1200$ and $R_{\eta} \approx 5$ to 100 , respectively. Mancktelow (2011) extended the solution of Bilby and Kolbuszewski (1977) to systems with power-law rheology and proposed that the effect of power-law viscous rheology is similar to an increase of the linear viscosity contrast between the competent and soft phase. This was also observed by Llorens et al. (2013b) from modelling of single-layer folding. 
Most of the studies discussed above deal with the deformation of isolated inclusions and thus ignore the influence of inclusion distribution and interactions between neighbouring inclusions. However, natural conglomerates are composed of multiple pebbles, usually resulting in interactions between neighbouring ones, especially in clast-supported conglomerates. A few studies have recognised that the deformation behaviour of inclusions and the bulk viscosity of the system are significantly affected by the concentration inclusions and their interaction (Gay, 1968; Bons and Cox, 1994; Mandal et al., 2003, 2005; Vitale and Mazzoli, 2005; Jessell et al., 2009; Mancktelow, 2011; Dabrowski et al., 2012; Marques et al., 2014). One effect of interaction between inclusions is that they behave as if they are softer than when they are isolated in the matrix (Mandal et al., 2003; Vitale and Mazzoli, 2005; Jessell et al., 2009). Therefore, the distribution of inclusions and their interactions are likely to affect the $R \eta$-boundaries between passive, deformable and rigid behaviour regimes. A further effect of increasing inclusion concentration and thus their interaction is that their rotation rate can be slowed down or inclusions may even stop rotating. This effect is associated with inclusion collisions or flow disturbances in the matrix (Ildefonse et al., 1992a,b; Samanta et al., 2003; Marques et al., 2014). Closely spaced inclusions can also form clusters or trains mechanically acting as single inclusions (Blumenfeld and Bouchez, 1988; Tikoff and Teyssier, 1994; Jessell et al., 
2009). According to Tikoff and Teyssier (1994), clusters of rigid inclusions are short-lived, while those composed of deformable inclusions with slipping boundaries remain coherent for longer times. However, it is still not entirely clear how the pebble concentration affects the $R \eta$-boundaries between different behaviour regimes and how rigid and deformable clusters form and develop respectively.

Numerical simulations of the deformation of inclusion-matrix systems were until recently limited to relatively low finite strains (e.g., Treagus et al., 2002; Treagus and Lan, 2003; Takeda and Griera, 2006; Jessell et al., 2009). Only recently have codes such as ELLE+VPFFT (Lebensohn, 2001; Lebensohn et al., 2009, 2011; Griera et al., 2013) and Milamin/MVEP2 (Dabrowski et al., 2008; Kaus, 2010) reached high shear strains (e.g., Dabrowski et al., 2012; Griera et al., 2013; Pouryazdan et al., 2017). In this study, we use the ELLE+VPFFT code to simulate viscous deformation of conglomerates with interactions between pebbles, varying the concentration of pebbles and viscosity ratio between pebbles and matrix, in both linear and power-law viscous rheologies, and up to high simple-shear strain. Our simulations produce a range of structures, depending on the various parameters. We compare the modelled conglomerate systems with a natural example of deformed conglomerates in the Wutai mountains area, North China Craton. 


\section{Methods}

We numerically model the viscous deformation of conglomerates in twodimensional simple shear. This study utilizes the open-source numerical modelling platform ELLE (Jessell et al., 2001; Bons et al., 2008; Piazolo et al., 2010; http://www.elle.ws), which has been applied to simulate a range of geological processes, such as strain localisation (Jessell et al., 2005; Gardner et al., 2017), folding (Llorens et al., 2013a,b), and deformation of two-phase rocks (Jessell et al., 2009), including those containing porphyroclasts and porphyroblasts (Griera et al., 2011, 2013), among many other studies. The deformation field is calculated using the VPFFT code, coupled with the ELLE software (Griera et al., 2013; Llorens et al., 2016b) for handling the data structure, re-meshing and pre- and post-processing of modelling results. Using a spectral solver, the VPFFT method finds a strain rate and stress field, associated with a kinematically admissible velocity field, which minimizes the average local work-rate under the compatibility and equilibrium constraints (Lebensohn, 2001; Griera et al., 2011). In general, the VPFFT approach has a better numerical performance than most Finite Element Methods (Prakash and Lebensohn, 2009; Roters et al., 2011), but it requires discretisation of the system into a regular grid. The VPFFT code requires periodic boundary conditions, which has the advantage that high-strain deformation in simple shear can be achieved without modifying the square model shape (a feature 
employed by, e.g., Jessell et al., 2009). The VPFFT together with the ELLE software platform has been widely used to simulation microstructural evolution in polar ice and halite (Llorens et al., 2016a,b; Steinbach et al., 2016, 2017; Jansen et al., 2016; Llorens et al., 2017; Gomez-Rivas et al., 2017) and deformation of inclusion-matrix systems (Griera et al., 2011, 2013). Although specific minerals can be modelled, our simulations here are not mineralspecific and the scale of the model should be regarded as distinctly larger than the individual grain scale.

As we use the same numerical approach as Griera et al. $(2011,2013)$ we refer to them for details of the numerical procedure and to Lebensohn (2001), Lebensohn et al. (2009, 2011), Montagnat et al. (2014), and Llorens et al. (2016b) for details of the VPFFT method. A model mineral with a hexagonal symmetry is used here (similar to Griera et al. 2011, 2013) to simulate the mechanical properties of the material, and deformation is allowed to be accommodated by glide along basal plane and along non-basal systems (i.e., pyramidal and prismatic; Fig. 1e). The resistance to shear of slip systems is simulated by means of the critical resolved shear stress (CRSS; $\tau$ ), which is set to the same value for the different slip systems, but is different for pebbles and matrix. This way, the materials are effectively isotropic and the lattice orientation of grid elements makes no discernible difference to the result and is assigned randomly at the beginning of the simulation. Griera et al. (2011) 
showed that with this VPFFT approach the rotation rate of a circular rigid inclusion embedded in a viscous isotropic matrix successfully follows the analytical solution of Jeffery (1922), thus validating this approach for the modelling of inclusion behaviour.

In our simulations with isotropic material properties (meaning that all slip systems have the same $\tau$ ), the relation between stress $(\sigma)$ and strain rate $(\dot{\varepsilon})$ of the material is defined by:

$\dot{\varepsilon}=A\left(\frac{\sigma}{\tau}\right)^{n}$,

where $n$ is the stress exponent and $A$ is a pre-exponential (scaling) factor, identical for all materials used in these simulations. The critical resolved shear stress $(\tau)$ of the matrix was set to unity $\left(\tau_{\text {pebble }}=1\right)$ in all cases. Pebbles are more competent than the matrix $\left(\tau_{\text {matrix }}<1\right)$. The stress exponents $(n)$ of pebble and matrix are always identical in one simulation, being either one or three (see Table 1). We define the viscosity ratio $R \eta$ between pebble and matrix using as a proxy the CRSS ratio $\left(R \eta=\tau_{\text {pebble }} / \tau_{\text {matrix }}\right)$. For linear rheology models $(n=1), R \eta$ is the real viscosity ratio. For $n=3$, the meaning of $R \eta$ is more complex, as viscosity is not constant in power-law materials. The effective viscosity ratio is defined by:

$$
R_{\eta}=\frac{\eta_{\text {pebble }}}{\eta_{\text {matrix }}}=\frac{\sigma_{\text {pebble }} / \dot{\varepsilon}_{\text {pebble }}}{\sigma_{\text {matrix }} / \dot{\varepsilon}_{\text {matrix }}}
$$

Two end members can be envisaged: (i) stress $(\sigma)$ is identical in both materials and strain rate $(\dot{\varepsilon})$ is partitioned (Reuss bound; Reuss, 1929), and (ii) strain 
rate $(\dot{\varepsilon})$ is identical in both materials and stress $(\sigma)$ is partitioned (Voigt or Taylor bound; Voigt, 1928). Effective viscosity ratios range between these two extremes:

Reuss: $\left(\sigma_{\text {pebble }}=\sigma_{\text {matrix }}\right): \frac{\eta_{\text {pebble }}}{\eta_{\text {matrix }}}=\frac{\sigma / \dot{\varepsilon}_{\text {matrix }}}{\sigma / \dot{\varepsilon}_{\text {pebble }}}=\frac{A\left(\frac{\sigma}{\tau_{\text {matrix }}}\right)^{n}}{A\left(\frac{\sigma}{\tau_{\text {pebble }}}\right)^{n}}=\left(\frac{\tau_{\text {pebble }}}{\tau_{\text {matrix }}}\right)^{n}=\left(R_{\eta}\right)^{n}$

Voigt: $\left(\dot{\varepsilon}_{\text {pebble }}=\dot{\varepsilon}_{\text {matrix }}\right): \frac{\eta_{\text {pebble }}}{\eta_{\text {matrix }}}=\frac{\sigma_{\text {pebble }} / \dot{\varepsilon}}{\sigma_{\text {pebble }} / \dot{\varepsilon}}=\frac{\tau_{\text {pebble }}\left(\frac{\dot{\varepsilon}}{A}\right)^{1 / n}}{\tau_{\text {matrix }}\left(\frac{\dot{\varepsilon}}{A}\right)^{1 / n}}=\frac{\tau_{\text {pebble }}}{\tau_{\text {matrix }}}=R_{\eta}$

We see that the real viscosity ratio for $n>1$ can range from $R \eta$ to $R \eta^{n}$, depending on the partitioning of stress $(\sigma)$ and strain rate $(\dot{\varepsilon})$.

The 2-D description of the model conglomerate is defined in the ELLE data structure as a contiguous set of polygons (termed flynns; Fig. 1a,b) and a set of unconnected nodes or Fourier points (termed unodes; Fig. 1f). The boundaries of flynns consist of straight segments that connect boundary nodes (termed bnodes; Fig. 1c,f) in either double- or triple-junctions. In this study, flynns define single-phase regions, with either matrix or pebble properties. State variables, such as stress, strain rate and lattice orientation, which can vary within flynns, are stored in the unodes that are distributed on a regular, rectangular 256x256 grid.

Starting models are square with a unit-cell size of $1 \times 1$ and contain 
approximately circular pebbles with a diameter of 0.075 times the unit-cell size. We use 24,70 and 100 randomly-placed pebbles, corresponding to pebble concentrations $(C)$ of $10 \%, 30 \%$ and $45 \%$, respectively. Velocity boundary conditions with constant strain rate are applied in the model, with top-to-theright simple shear deformation. Displacements $(\Delta \boldsymbol{x})$ are derived from a linear integration of velocities $(\boldsymbol{v})$ over a small time increment $(\Delta t): \Delta \mathbf{x}=\boldsymbol{v} \cdot \Delta t$, to achieve shear-strain increments of $\Delta y=0.02$ /step. The velocity field is used to incrementally move boundary nodes that define the flynn boundaries and, hence, the pebble-matrix boundaries. The model is repositioned to the initial square unit cell and material properties (pebble or matrix) are mapped back on the regular, square grid, as is required by the VPFFT method, before each next deformation step (Fig. 1d).

Three input parameters are systematically varied in the simulations (Table 1): (1) the concentration $(C)$ of pebbles, (2) the stress exponent for linear or power-law viscous rheology ( $n=1$ or 3$)$, and (3) the viscosity ratio $(R \eta)$. To visualise the distribution of the strain rate intensity, we plot the Von Mises strain rate (or equivalent strain rate) normalized to the bulk Von Mises strain rate for each unode. The Von Mises strain rate is the second invariant of the symmetric strain rate tensor. The distribution of the accumulated finite vorticity $(W)$ and strain $\left(R_{s}\right)$ for a strain increment are visualized by integrating the incremental stain rate tensor of each unode from each simulation step 
(Steinbach, 2017). Vorticity is the mean rotation angle (in radians) of material lines in a deforming material (Means et al., 1980). Considering the minor deformation of rigid pebbles in some simulations, we here use vorticity to visualize and discuss pebble rotation instead of the vorticity number (Means et al., 1980). We measure the ratios $\left(R_{f}\right)$ between long and short axes of pebbles and the orientations of the long axes $(\phi)$ from the shear plane at different finite strains, using the particle analysis routine of the freeware ImageJ software (Schneider et al., 2012; http://imagej.nih.gov/ii). The arithmetic means of $R_{f}$ and $\phi$ are used for the statistical analysis of pebble deformation and rotation (cf. Lisle, 1977).

Insert Fig.1

Insert Table 1

\section{Results}

The geometries of deformed conglomerates for different $R \eta$ and values of the stress exponent $(n)$ are shown in Fig. 2 for a finite strain of ten $(\gamma=10)$. Selected movies (Table 1) showing the evolution of the structure and normalised strain rate can be found in appendix $A$. 
Insert Fig. 2

Our simulations cover the three types of deformation behaviour of pebbles in deformed conglomerates: (i) passive, (ii) deformable and (iii) rigid (Fig. 2). For a power-law viscous rheology $(n=3)$, passive deformation of pebbles is observed at $R \eta=2$ and high pebble concentrations ( $C=45 \%)$. The same passive behaviour can be observed in systems with linear viscosity $(n=1)$, in simulations with $R \eta=2$ (all range of pebble concentrations) and with $R \eta=5$ with high pebble concentration $(C=45 \%)$. Rigid pebble behaviour, with minor distortion and only rotation, is observed at high $R \eta$. For $n=3$, pebbles behave rigidly when $R \eta \geq 5$ at $C=10 \%$ and $30 \%$, and at $C=45 \%$ for $R \eta=10$ only. The same pattern is observed for models with $n=1$, with pebbles behaving rigidly at $R \eta \geq 15$ at $C=10 \%$, and at $C=30 \%$ only at $R \eta=45$. In between these cases pebbles deform significantly, but distinctly less than the matrix. The deformation behaviour of pebbles in the simulations with $R \eta=2, R \eta=5$ and $R \eta=10$ for $n=3$ are approximately consistent with those in the simulations with $R \eta=5, R \eta=15$ and $R \eta=45$ for $n=1$, respectively. Pebbles in the deformable regime show elongate mica fish and $\sigma$-clast shapes (Fig. 2a,b; Passchier and Trouw, 2005). The deformed flynn boundaries in the matrix serve as a proxy for the expected trend that a foliation would develop by wrapping around rotating pebbles (Fig. 2a,b). 
With increasing finite strain, passive and deformable pebbles keep stretching (increasing their $\left.R_{f}\right)$ and their long axes rotate towards the shear plane $(\phi=0)$ (Fig. 3). Some of deformable and rigid pebbles show pulsating behaviour. In this case their long axes rotate towards and beyond the shear plane, while their $R_{f}$ values remain low $(<3)$. The $R_{f} \phi$ graph (Fig. 3) thus shows two types of paths. In the first $\phi$ consistently decreases towards $\phi=0$ and $R_{f}$ increases towards $R_{f}=\infty$ with progressive strain. In the second case, pebbles remain "trapped" at $R_{f}$ smaller than about three and variable $\phi$.

Insert Fig. 3

At a low pebble concentration of $C=10 \%$, the mean rotation of rigid pebbles is similar to the ideal rotation of the single rigid inclusion calculated by Jeffery's (1922) solution (Fig. 4). With increasing concentration, the mean rotation of rigid pebbles decreases (Fig. 4). However, the variation in rotation rate between pebbles increases and some pebbles actually rotate faster than the prediction by Jeffery's (1922).

Insert Fig. 4

As expected, strain rate and vorticity are highly variable in the matrix, especially at high $R \eta$ (Fig. 5). An increase in $R \eta$ and $C$ enhances strain rate 
partitioning. The vorticity maps (Fig. 5, columns IV-VI) illustrate the sense of rotation of local deformation. Some of the highest strain rates (red tones in Fig. 5, columns II-III) are associated with a clockwise rotation (dextral shear, red tones in Fig. 5, columns $\mathrm{V}-\mathrm{VI}$ ) and develop in nearly horizontal zones, thus indicating the activity of synthetic C-type shear bands. At high $R \eta$ and $C$, vertical, C"-type shear bands with significantly elevated strain rates and negative vorticity (i.e., sinistral shear-sense) also form.

Insert Fig. 5

Clusters formed by the association of several closely spaced deformable or rigid pebbles can behave as effectively single objects. They form with increasing finite strain in simulations with high pebble concentrations such as $30 \%_{R \eta 10}^{n 3}$ and $30 \%_{R}^{n 3} \eta_{2}$ (Figs. 6, 7). In the simulations with rigid pebbles such as $30 \% R \eta 10$, antithetic shear zones initially form perpendicular to the shear plane and progressively rotate toward it (Figs. 6, 7). The cluster formed by rigid pebbles rotate less than the mean rotation of individual pebbles and Jeffery's (1922) rotation model in simulation $30 \% \stackrel{n 3}{n 3}$ (Fig. 4).

Insert Fig. 6 \& 7

\section{Discussion}




\subsection{Pebble deformation}

Passive, deformable and rigid behaviour of pebbles are observed in our simulations with different $R \eta$ and for different $C$ (Fig. 2). For a given $C$ value, decreasing $R \eta$ enhances pebble deformation (Figs. 2, 3). This is consistent with previous studies, which suggest that the deformation behaviour of inclusions is strongly influenced by $R \eta$ (e.g., Gay, 1968; Bilby and Kolbuszewski, 1977; Lisle et al., 1983; Treagus and Treagus, 2001; Mandal et al., 2003; Takeda and Griera, 2006; Jiang, 2013; Qu et al., 2016). In our simulations, pebble concentration $(C)$ is another important factor. In models with high $C$ closely spaced pebbles interact with their neighbours, thus enhancing their deformation (Figs. 2, 3). In both cases of linear and power-law viscous rheologies, the effect of increasing $C$ is similar to a decrease of $R \eta$, and vice versa. The pebbles deform as if they are "softer" in models with higher $C$. An increase in $C$ and pebble interaction slightly reduce the mean rotation rate of rigid pebbles, which is consistent with previous studies (Fig. 4; Ildefonse et al., 1992a,b; Samanta et al., 2003; Marques et al., 2014). However, variation in pebble rotation rate increases with increasing $C$ (Fig.4).

Previous studies have suggested that an isolated inclusion at $R \eta>$ ca. 20-50 deforms rigidly if rheology is linear viscous, even at high finite strain (Gay, 
1968; Bilby et al., 1975; Weijermars, 1993; Treagus and Treagus, 2001). Our $n=1$ simulations show that pebbles in simulations with $R \eta \geq 15$ behave rigidly for a low $C=10 \%$ with minor interactions between neighbour pebbles. However, at a high $C$ of $45 \%$, pebbles interact with their neighbours and are deformable even at $R \eta=45$. The reported boundary between deformable and rigid from $R \eta=10-50$ is thus confirmed by our simulations, with the lower end representing isolated inclusions and the higher end closely packed inclusions. According to Bilby and Kolbuszewski, (1977), a single inclusion behaves passively at $R \eta \leq 2$ for a linear viscous rheology. This is supported by our results for $C=10 \%$. Again, raising the pebble concentration also raises the transition $R \eta$, here up to about 5 for $C=45 \%$ (Fig. $2 b$ ). Similar trends are found for a power-law rheology with $n=3$ (Fig. 2a).

The range of $R \eta$ for deformable pebbles is quite narrow, between 2 and 15 for $n=1$ and $C=10 \%$, and at higher $C$ still within one or two orders of magnitude. However, passive and deformable pebbles appear to be the most common in nature, with no examples of rigid-pebble behaviour at high strains known to the authors. This suggests that viscosity contrasts between materials that constitute a conglomerate are usually low. Generally low viscosity contrasts are also indicated by fold geometry and cleavage refraction (Treagus, 1999).

In the strict definition, all inclusions are deformable when not perfectly rigid. In 
practice, it is difficult to determine whether natural pebbles exhibited perfectly passive or rigid behaviour. We therefore use three fields in the mean $R_{f} \phi$ plot (Fig. 8) based on the structures shown in Fig. 2 and the data in Fig. 3: (i) effectively passive, (ii) deformable and (iii) effectively rigid. Effectively passive pebbles stretch significantly and achieve an average aspect ratio $\left(R_{f}\right)$ of $\geq 20$ at high finite strain. Because of the strong stretching, there is no discernable deflection or wrapping of a foliation (if present) around the pebbles. Effectively rigid pebbles maintain an average aspect ratio $\left(R_{f}\right)$ of less than about two, even at high finite strains. Any developing foliation would show strong deflections around the nearly equidimensional pebbles. Deformable pebbles occupy the field in between the previous two in Fig. 8. Pebbles are visible stretched, but a foliation would still be deflected around the pebbles, indicating even higher strains in the matrix. The field for deformable pebbles can be divided into two: pulsating behaviour (high $R \eta$ and/or low $C$ ) and permanently stretching (low $R \eta$ and/or high $C$ ).

In simple shear, initially approximately equidimensional pebbles follow trajectories in $R_{f}-\phi$ space, starting from around $R_{f}=1$ and $\phi=45^{\circ}$ and moving towards one of the two fabric attractors with increasing strain. $R_{f}$ and $\phi$ values can be measured in naturally deformed pebbles and their means can be plotted in the $R_{f}-\phi$ graph to gain an estimate of their type of behaviour and the amount of strain, in case of permanently stretching pebbles. An example is 
given further below.

Insert Fig. 8

Effectively passive and deformable pebbles in deformed conglomerates are the most important and thus most widely investigated, as their shape fabrics can be used for strain analysis and rheology studies (e.g., Gay, 1968; Lisle et al., 1985; Treagus and Treagus, 2002; Czeck et al., 2009). In our simulations, for a given $R \eta$, an increasing $C$ enhances the aspect ratios $\left(R_{f}\right)$ of pebbles but reduces their rotation (Figs. 3, 4; Ildefonse et al., 1992a,b; Samanta et al., 2003; Mandal et al., 2004; Marques et al., 2014). Our simulations allow comparison with existing models for the evolution of mean $R_{f}$ as a function of strain $\left(R_{s}\right)$, such as the equation proposed by Gay (1968):

$\ln \left(R_{f}\right)=\frac{5 \cdot \ln \left(R_{s}\right)}{3+2 R_{\eta G a y}} \Leftrightarrow R_{\eta G a y}=\frac{2.5 \cdot \ln \left(R_{s}\right)}{\ln \left(R_{f}\right)}-1.5$,

where $R \eta_{\text {Gay }}$ is the calculated apparent viscosity ratio.

Another solution purposed by Bilby et al. (1975) is also widely accepted for the calculations of strain and viscosity ratio. However, Treagus and Treagus (2002) showed no distinct difference between the equations of Gay (1968) and Bilby et al. (1975) and suggested to use Gay's (1968) equation for practical geological applications, which we also use here. It should be noted that Eq. (4) applies to a linear viscosity only. However, it may also serve to gain insight in 
the apparent viscosity contrast for the cases where $n \neq 1$.

Figure 9a compares our simulations with the $R_{f}$-strain curves from Gay (1968). The development of shape fabrics of pebbles is different from the predictions using Gay's (1968) theory for single inclusion in linear viscous rheology. Most of our results show larger $R_{f}$-values with increasing finite strain than predicted with Eq. (4). Pebble concentration has a critical effect on shape fabrics in our simulations, especially at high finite strain. For low $C=10 \%$, the shape development is similar to that in Gay's (1968) theory at low finite strain $\left(R_{s}\right.$ $<10)$. However, the simulations show an increasing deviation from the corresponding theory solution at middle to high finite strain $\left(R_{s}>10\right)$, even for a very low $C(10 \%)$.

We use Eq. (4) to calculate apparent viscosity ratios $\left(R \eta_{\text {Gay }}\right)$ and compare these with the known $R \eta$ in our simulations (Fig. 9b). For $n=1$ and $C=10 \%$, $R \eta_{\text {Gay }} \approx R \eta$ within error. However, at higher $C$, but same $R \eta$, pebbles deform more with the result that Gay's (1968) solution tends to underestimate the true viscosity ratio $(R \eta)$. The concept of an apparent viscosity ratio could potentially be used for power-law rheologies, where Fig. $9 \mathrm{~b}$ gives $R \eta_{\text {Gay }}>R \eta$ for $n=3$. However, we did not find a consistent relationship between $R \eta$ and $R \eta_{\text {Gay. }}$. 


\subsection{Nature of pebble clusters}

In some simulations with rigid and deformable pebble behaviour, closely spaced pebbles form a cluster that behaves as a single pebble, resulting in low strain rate and consistent vorticity within the cluster (Figs. 6, 7). There are two types of clusters depending on their deformation behaviour: rigid and deformable clusters.

In rigid clusters, the pebbles rotate together and not relative to each other (Fig. 6). However, they do not survive long, as after a short deformation increment, strain begins to localise in the matrix between pebble clusters until the clusters break up. Figure 6 gives an example of the formation and disintegration of rigid clusters in the simulation $30 \% \begin{gathered}n 3 \\ R \eta 1\end{gathered}$. Pebbles $\mathrm{A}, \mathrm{B}$ and $\mathrm{C}$ form a cluster from a finite strain of $\gamma=4$ (Fig. 6a-c). There is no shearing of the matrix between them (Fig. 6b) and the pebbles and matrix in between together rotate at the same rate (Fig. 6c), which is similar to that of other individual pebbles in the model. This cluster survives until a finite strain of $\gamma=4.6$ is reached, at which point the cluster disintegrates and each pebble behaves independently (Fig. 6d-f).

Pebbles A and B move towards each other again until they form a new cluster during the finite strain interval between $\gamma=6.3$ and 6.7 (Fig. $6 \mathrm{~g}-\mathrm{i}$ ). 
In Fig. 6, single pebbles rotate on average ca. $13.6^{\circ}$ over a finite strain increment of $\Delta y=0.5$, whereas the cluster formed by pebbles $A, B$ and $\mathrm{C}$ rotates over ca. $12.6^{\circ}$ from $\gamma=4$ to 4.5 ( $\Delta \gamma=0.5$; Fig. 4 ). The rotation of the cluster is less than that of individual pebbles as well as the finite rotation according to Jeffery's (1922) analytical solution $\left(14.3^{\circ}\right)$. This is consistent with previous studies suggesting that clusters rotate more slowly than single pebbles (Ildefonse et al., 1992a; Jessell et al., 2009). However, cluster rotation is still within the range of individual pebble rotations. Considering the short-lived character of rigid clusters, our results suggest that the formation of rigid clusters does not strongly affect the rotation of pebbles at large finite strains.

Figure 7 gives an example of evolution of deformable clusters in the simulation $30 \%{ }_{R \eta 2}^{n 3}$. Contrary to rigid clusters, clusters of deformable pebbles deform into shapes similar to those of isolated individual pebbles (Fig. 7). The strain distribution in some deformable clusters is heterogeneous, as is the case for isolated pebbles. Deformable clusters survive for longer strain increments, some even persist until the end of the simulations (Fig. 7j). In Fig. 7, clusters A and B form at $\gamma=3.2$ and 3.4, and collapse at $\gamma=5.4$ and 7.2, respectively (Fig. 7.a-f,j). There is no shearing of the matrix between them (Fig. $7 b, c)$ and the pebbles and matrix in between deform jointly at the same rate (Fig. 7b). However, cluster $\mathrm{C}$ forms at $\gamma=4.6$ and remains up to $\gamma=10$ (Fig. $7 \mathrm{~g}$-j). Deformable isolated pebbles and clusters rotate rapidly towards the shear 
direction and then keep on elongating with minor further rotation in response to progressive deformation. The slow rotation facilitates the stability of deformable clusters, as opposed to rigid-pebble clusters.

Our observations can be compared with the models proposed by Tikoff and Teyssier (1994). They suggested three models of trains (clusters) based on Jeffery's (1922) and March's (1932) theories: (1) Jeffery-rotating train model, (2) March-rotating train model and (3) March-fixed train model. In the Jefferyrotating train model, both inclusions and trains rotate rigidly according to Jeffery's (1922) theory, and trains are short-lived cf. Fig. 6. In the Marchrotating train and the March-fixed train models, it is assumed that there is slip at the interface between inclusions and matrix and the shear localisation takes place around the inclusions. Inclusions rotate according to March's (1922) theory for passive markers and are not allowed to rotate past the shear plane. Trains persist for longer deformation increments in the March-rotating train model, whereas trains remain fixed in March-fixed train model. The behaviour of rigid clusters (Fig. 6) in our simulations is consistent with the Jeffery-rotating train model. Our deformable clusters are present for longer deformation increments (Fig. 7), which is similar to the March-rotating and the March-fixed train models, even though our simulations do not allow slip along the pebble boundaries. 


\section{Natural example in North China Craton}

Our simulation results are compared with deformed Proterozoic conglomerates in the Hutuo Group, North China Craton. The Hutuo group is exposed in the Wutai Mountains area, in the Trans-North China Orogen (TNCO), where the Eastern and Western Blocks of the North China Craton collided at $\sim 2.5$ or $\sim 1.85$ Ga (e.g., Zhao et al., 2001; Li and Kusky, 2007; Fig. 10a,b). The group is divided into three subgroups: the Doucun, Dongye and Guojiazhai subgroups from base to top (Bai, 1986). The deformed conglomerates have been interpreted as basal conglomerates at the base of Doucun Subgroups, which unconformably overlay the Wutai Group and Neoarchean granitoids and were deposited after $\sim 2.2$ or $\sim 1.9$ Ga (e.g., Bai, 1986; Zhang et al., 2012; Du et al., 2017).

Insert Fig. 10

In the Yangjiaogou area, the deformed conglomerates mainly consist of pebbles composed of deformed banded iron formations (BIFs) embedded in a foliated greenschist matrix (Fig. 10c,d). Matrix-supported conglomerates with a pebble concentration of about $7 \%$ appear strongly deformed with limited interactions between pebbles. Pebbles are visible stretched, but the foliation in the matrix is deflected around the pebbles. We therefore classify the pebbles 
as deformable. Asymmetric structures, such as sigmoidal pebbles and rolling structures indicate top-to-SW shearing (Fig. 10c). The stretching direction of boudinage quartz veins, which is oblique to the shear plane, also suggests a top-to-SW shearing (Fig. 10c). Although the exact kinematic vorticity of deformation could not be determined, we assume here that deformation was approximately simple shear because of the consistent asymmetry and sense of shear of all structures.

We use the geometries of boudinaged quartz veins to estimate the amount of shear strain, using the equations B.12 and 13b' of Ramsay and Huber (1987). The calculated finite strain is either 3.7 or 8.7 depending on the initial orientation of the vein (ca. $22^{\circ}$ or $-22^{\circ}$ ) (more details of calculation see Appendix B). The formation of rolling structures (Fig. 10c) requires a significant rotation of pebbles of $\geq 150^{\circ}$ at high finite strain. Together with the deflection of the foliation around the pebbles, this suggests that the finite strain is ca. 8.7 , and not ca. 3.7. A low $R_{f}$ of $\sim 3.4$ and an orientation of long-axes $(\phi)$ nearly parallel to the shear plane $\left(\phi \approx 2.9^{\circ}\right)$ was obtained from an analysis of 82 pebbles. The measurements and structures can be compared with our simulations with $10 \%$ pebble concentration characterized by minor interactions and the deflected foliation around pebbles (Fig. 10d,e). The mean of $\phi$ is consistent with that in simulation $10 \%_{R \eta 5}^{n 1}$ (Appendix A, Movie 1) at a finite strain of 8 to 10 , whereas the mean of aspect ratios $\left(R_{f}\right)$ is lower than that in 
simulation $10 \%{ }_{R \eta 5}^{n 1}$ at a finite strain of 8 to 10 , thus suggesting a higher viscosity ratio (Fig. 11). An additional simulation $\left(10 \%{ }_{R \eta 8}^{n 1}\right)$ with $C=10 \%$ pebbles and a lower viscosity ratio $(R \eta=8)$ in linear rheology $(n=1)$, was run for comparison with the deformed conglomerates in the Yangjiaogou area (Fig. 11). According to our $R_{f} \phi$ plot (Fig. 8), we suggest that the viscosity ratio of deformed conglomerates in the Yangjiaogou area is 5 to 8 for a linear rheology $(n=1)$ and 2 to 5 for a power-law rheology $(n=3)$. The plot also suggests a finite strain of $\gamma \approx 6$, close to the $\gamma \approx 8.7$ derived from the strain analysis on the boudinaged vein.

Insert Fig. 11

The example from the Wutai Mountains shows that the graphs obtained from our simulations may aid to quantify the amount of deformation with relatively simple $R_{f}$ and $\phi$ measurements. Not only does one obtain an estimate of the finite strain, but also insight in the relative rheological properties of the lithologies involved. Together with regional structural geological studies (e.g., Li et al., 2010; Trap et al., 2012; Zhang et al., 2012), this may help to elucidate the regional deformation and tectonics after deposition of the conglomerates of the Hutuo Group.

\section{Conclusions}


We use numerical simulations to model the viscous simple-shear deformation of conglomerates with different degrees of interaction between pebbles, by varying the concentration of pebbles and viscosity ratio between pebbles and matrix, in both linear and power-law viscous rheologies. Our results lead to the following conclusions:

1. Pebbles can behave as rigid, deformable and passive inclusions depending on both the viscosity ratio and their concentration.

2. The effect of increasing pebble concentration is similar to a decrease of viscosity ratio between pebbles and matrix, and vice versa. An increase in concentration and interaction enhances the pebble distortion, but reduces the mean rotation of rigid pebbles.

3. Clusters of closely spaced pebbles can behave as single objects. Rigid clusters continue rotating, but survive for only a short strain interval.

Deformable clusters initially rotate rapidly towards the shear direction, and then keep on elongating with minor rotation. The slower rotation facilitates the stability of deformable clusters.

4. A mean $R_{f}-\phi$ plot is suggested to gain an estimate of pebble deformation behaviour and the amount of strain in cases of permanently stretching pebbles.

5. A case study on deformed conglomerates of the Hutuo Group, North China 
Craton, illustrates the use of the use of the mean $R_{f}-\phi$ plot, giving an estimate of the finite strain and viscosity contrast between pebbles and matrix.

\section{Acknowledgments}

Fieldwork in the Wutai Mountains area, China was supported by the China Geological Survey (grant No. 12120114076401). We appreciate the help for the field work from Zhongbao Zhao, Changshun Wen, Chao Li and Gongyao

Xu and the constructive suggestions from Guoli Yuan, Zhongbao Zhao and Changshun Wen. HR thanks the financially support by the China Scholarship Council (CSC; No. 201506400014).

\section{References}

Bai, J., 1986. The early Precambrian geology of Wutaishan. Tianjin Science and Technology Press, Tianjin.

Bilby, B.A., Eshelby, J.D., Kundu, A.K., 1975. The change of shape of a viscous ellipsoidal region embedded in a slowly defomring matrix having a different viscosity. Tectonophysics 28, 265-274. 
Bilby, B.A., Kolbuszewski, M.L., 1977. The finite deformation of an inhomogeneous in two-dimensional slow viscous incompressible flow. Proceedings of Royal Society A355, 335-353.

Blumenfeld, P., Bouchez, J.-L., 1988. Shear criteria in granite and migmatitc deformed in magmatic and solid state. Journal of Structural Geology 10, 361-372.

Bons, P.D., Cox, S.J.D. 1994. Analogue experiments and numerical modelling on the relation between microgeometry and flow properties of polyphase materials. Materials Science and Engineering A175, 237-245.

Bons, P.D., Koehn, D., Jessell, M.W.(Eds), 2008. Microdynamics Simulation. In: Lecture Notes in Earth Sciences 106. Springer, Berlin.

Czeck, D.M., Fissler, D.A., Horsman, E., Tikoff, B., 2009. Strain analysis and theology contrasts in polymictic conglomerates: An example from the Seine metaconglomerates, Superior Province, Canada. Journal of Structural Geology 31, 1365-1376.

Czeck, D.M., Hudleston, P.J., 2003. Testing models for obliquely plunging lineations in transpression: a natural example and theoretical discussion. Journal of Structural Geology 25, 959-982.

Dabrowski, M., Krotkiewski, M., Schmid, D.W., 2008. MILAMIN: MATLABbased finite element method solver for large problems. Geochem. Geophys. Geosyst. 9, Q04030, doi:10.1029/2007GC001719.

Dabrowski, M., Schmid, D.W., Podladchikov, Y.Y., 2012. A two-phase 
composite in simple shear: Effective mechanical anisotropy development and localization potential. Journal of Geophysical Research 117, B08406, doi:10.1029/2012JB009183.

Du, L., Yang, C., Wyman, D.A., Nutman, A.P., Zhao, L., Lu, Z., Song, H., Geng, Y., Ren, L., 2017. Zircon U-Pb ages and Lu-Hf isotope compositions from clastic rocks in the Hutuo Group: Further constraints on Paleoproterozoic tectonic evolution of the Trans-North China Orogen. Precambrian Research 303, 291-314.

Dunnet, D., 1969. A technique of finite strain analysis using elliptical particles. Tectonophysics 7, 117-136.

Eshelby, J.D., 1957. The determination of the elastic field of an ellipsoidal inclusion, and related problems. Proceedings of the Royal Society A241, 376-396.

Fletcher, R.C., 2004. Anisotropic viscosity of a dispersion of aligned elliptical cylindrical clasts in viscous matrix. Journal of Structural Geology 26, 1977-1987.

Flinn, D., 1956. On the deformation of the Funzie conglomerate, Fetlar, Shetland. The Journal of Geology 64, 480-505.

Freeman, B., Lisle, R.J., 1987. The relationship between tectonic strain and the three-dimensional shape fabrics of pebbles in deformed conglomerates. Journal of the Geological Society 144, 635-639.

Fry, N., 1979. Random point distributions and strain measurement in rocks. 
Tectonophysics 60, 89-105.

Gardner, R., Piazolo, S., Evans, L., Daczko, N., 2017. Patterns of strain localization in heterogeneous, polycrystalline rocks-a numerical perspective. Earth and Planetary Science Letters 463, 253-265.

Gay, N.C., 1968. Pure shear and simple shear deformation of inhomogeneous viscous fluids. 1. Theory. Tectonophysics 5, 211-234.

Gomez-Rivas, E., Griera, A., Llorens, M.-G., Bons, P. D., Lebensohn, R. A., Piazolo, S., 2017. Subgrain rotation recrystallization during shearing: Insights from full-field numerical simulations of halite polycrystals. Journal of Geophysical Research: Solid Earth 122, doi:10.1002/2017JB014508.

Griera, A., Bons, P. D., Jessell, M. W., Lebensohn, R. A., Evans, L., GomezRivas, E., 2011. Strain localization and porphyrocalst rotation. Geology $39,275-278$.

Griera, A., Llorens, M.-G., Gomez-Rivas, E., Bons, P. D., Jessell, M. W., Evans, L. A., Lebensohn, R., 2013. Numerical modelling of porphyroclast and porphyroblast rotation in anisotropic rocks. Tectonophysics 587, 4-29. Ildefonse, B., Launeau, P., Bouchez, J.L., Fernandez, A., 1992a. Effect of mechanical interactions on the development of shape preferred orientations: a two-dimensional experimental approach. Journal of Structural Geology 14, 73-83.

Ildefonse, B., Sokoutis, D., Mancktelow, N.S., 1992b. Mechanical interactions between rigid particles in a deforming ductile matrix. Analogue 
experiments in simple shear flow. Journal of Structural Geology 14, 12531266.

Jansen, D., Llorens Verde, M.-G., Westhoff, J., Steinbach, F., Kipfstuhl, S., Bons, P.D., Griera, A., Weikusat, I., 2016. Small-scale disturbances in the stratigraphy of the NEEM ice core: observations and numerical model simulations. The Cryosphere 10, 359-370.

Jeffery, J.B., 1922. The motion of ellipsoidal particles immersed in viscous fluid. Proceedings of Royal Society London A102, 161-179.

Jessell, M., Bons, P.D., Evans, L., Barr, T., Stüwe, K., 2001. Elle: the numerical simulation of metamorphic and deformation microstructures, Computers \& Geosciences 27, 17-30.

Jessell, M.W., Bons, P.D., Griera, A., Evans, L.A., Wilson, C.J.L., 2009. A tale of two viscosities. Journal of Structural Geology 31, 719-736.

Jessell, M.W., Siebert, E., Bons, P.D., Evans, L., Piazolo, S., 2005. A new type of numerical experiment on the spatial and temporal patterns of localization of deformation in a material with a coupling of grain size and rheology. Earth and Planetary Science Letters 239, 309-326.

Jiang, D., 2007a. Numerical modeling of the motion of deformable ellipsoidal objects in slow viscous flows. Journal of Structural Geology 29, 435-452. Jiang, D., 2007b. Numerical modeling of the motion of rigid ellipsoidal objects in slow viscous flows: A new approach. Journal of Structural Geology 29, 189-200. 
Jiang, D., 2013. The motion of deformable ellipsoids in power-law viscous materials: Formulation and numerical implementation of a micromechanical approach applicable to flow partitioning and heterogeneous deformation in Earth's lithosphere. Journal of Structural Geology 50, 22-34.

Jiang, D., Bentley, C., 2012. A micromechanical approach for simulating multiscale fabrics in large-scale high-strain zones: Theory and application. Journal of Geophysical Research 117, B12201, doi:10.1029/2012JB009327.

Johnson, S.E., Lenferink, H.J., Marsh, J.H., Price, N.A., Koons, P.O., West Jr., D.P., 2009a. Kinematic vorticity analysis and evolving strength of mylonitic shear zones: New data and numerical results. Geology 37, 1075-1078.

Johnson, S.E., Lenferink, H.J., Price, N.A., Marsh, J.H., Koons, P.O., West Jr., D.P., Beane, R., 2009b. Clast-based kinematic vorticity gauges: the effects of slip at matrix/clast interfaces. Journal of Structural Geology 31, $1322-1339$.

Kaus, B., 2010. Factors that control the angle of shear bands in geodynamic numerical models of brittle deformation. Tectonophysics 484, 36-47. Lebensohn, R.A., 2001. N-site modeling of a 3D viscoplastic polycrystal using Fast Fourier Transform. Acta Materialia 49, 2723-2737. 
Lebensohn, R.A., Idiart, M., Castañeda, P.P., Vincent, P.-G., 2011. Dilatational viscoplasticity of polycrystalline solids with inter-granular cavities. Philos. Maga. 91, 3038-3067.

Lebensohn, R.A., Montagnat, M., Mansuy, P., Duval, P., Meysonnier, J., Philip, A., 2009. Modeling viscoplastic behavior and heterogeneous intracrystalline deformation of columnar ice polycrystals. Acta Materialia $57,1405-1415$.

Li, J.H., Kusky, T.M., 2007. A late Archean foreland fold and thrust belt in the North China Craton: Implications for early collisional tectonics. Gondwana Research 12, 47-66.

Li, S., Zhao, G., Wilde, S.A., Zhang, J., Sun, M., Zhang, G. and Dai, L., 2010. Deformation history of the Hengshan-Wutai-Fuping Complexes: implications for the evolution of the Trans-North China Orogen. Gondwana Research 18, 611-631.

Lisle, R.J., 1977. Estimation of the tectonic strain ratio from the mean shape of deformed elliptical markers. Geologie en Mijnbouw 56, 140-144.

Lisle, R.J., 1979. Strain analysis using deformed pebbles: the influence of initial pebble shape. Tectonophysics 60, 263-277.

Lisle, R.J., 1985. The use of the orientation tensor for the description and statistical testing of fabric. Journal of Structural Geology 7, 115-117.

Lisle, R.J., Rondeel, H.E., Doorn, D., Brugge, J. and Van de Gaag, P., 1983. Estimation of viscosity contrast and finite strain from deformed elliptical 
inclusions. Journal of Structural Geology 5, 603-609.

Llorens, M.-G., Bons, P. D., Griera, A., Gomez-Rivas, E., 2013a. When do folds unfold during progressive shear?. Geology 41, 563-566.

Llorens, M.-G., Bons, P. D., Griera, A., Gomez-Rivas, E., Evans, L. A., 2013b. Single layer folding in simple shear. Journal of Structural Geology 50, 209220.

Llorens, M.-G., Griera, A., Bons, P. D., Lebensohn, R., Evans, L., Jansen, D., Weikusat, I, 2016a. Full-field prediction of ice dynamic recrystallisation under simple shear conditions, Earth and Planetary Science Letters 450, 233-242.

Llorens, M.-G., Griera, A., Bons, P.D., Roessiger, J., Lebensohn, R., Evans, L., Weikusat, I., 2016b. Dynamic recrystallisation of ice aggregates during co-axial viscoplastic deformation: a numerical approach. Journal of Glaciology 62, 359-377.

Llorens, M.-G., Griera, A., Steinbach, F., Bons, P.D., Gomez-Rivas, E., Jansen, D., Roessiger, J., Lebensohn, R.A., Weikusat, I., 2017. Dynamic recrystallization during deformation of polycrystalline ice: insights from numerical simulations. Philosophical Transactions Series A: Mathematical, physical, and engineering sciences 375,2086 , doi:10.1098/rsta.2015.0346.

Mancktelow, N.S., 2002. Finite-element modelling of shear zone development in viscoelastic materials and its implications for localisation of partial 
melting. Journal of Structural Geology 24, 1045-1053.

Mancktelow, N.S., 2011. Deformation of an elliptical inclusion in twodimensional incompressible power-law viscous flow. Journal of Structural Geology 33, 1378-1393.

Mandal, N., Misra, S., Samanta, S.K., 2004. Role of weak flaws in nucleation of shear zones: an experimental and theoretical study. Journal of Structural Geology 26, 1391-1400.

Mandal, N., Samanta, S.K., Bhattacharyya, G., Chakraborty, C., 2003. Deformation of ductile inclusions in a multiple inclusion system in pure shear. Journal of Structural Geology 25, 1359-1370.

Mandal, N., Samanta, S.K., Bhattacharyya, G., Chakraborty, C., 2005. Rotation behaviour of rigid inclusions in multiple association: insights from experimental and theoretical models. Journal of Structural Geology 27, 679-692.

March, A., 1932. Mathematische Theorie der Regelung nach der Korngestah bei affiner Deformation. Zeitschrift für Kristallographie - Crystalline Materials 81, 285-297.

Marques, F.O., Bose, S., 2004. Influence of a permanent low-friction boundary on rotation and flow in rigid inclusion/viscous matrix systems from an analogue perspective. Tectonophysics 382, 229-245.

Marques, F.O., Mandal, N., Taborda, R., Antunes, J.V., Bose, S., 2014. The behaviour of deformable and non-deformable inculsions in viscous flow. 
Earth-Science Reviews 134, 16-69.

Means, W.D., Hobbs,B.E., Lister, G.S., Williams, P.F., 1980. Vorticity and noncoaxiality in progressive deformations. Journal of Structural Geology 2, 371-378.

Montagnat, M., Castelnau, O., Bons, P.D., Faria, S.H., Gagliardini, O., GilletChaulet, F., Grennerat, F., Griera, A., Lebensohn, R.A., Moulinec, H., Roessiger, J., Suquet, P., 2014. Multiscale modeling of ice deformation behavior. Journal of Structural Geology 61, 78-108.s

Passchier, C.W., Trouw, R.A.J., 2005. Microtectonics. Springer, Berlin.

Piazolo, S., Jessell, M.W., Bons, P.D., Evans, L., Becker, J.K. 2010. Numerical simulations of microstructures using the Elle platform: A modern research and teaching tool. Journal of the Geological Society of India 75, 110-127.

Piazolo, S., Passchier, C.W., 2002. Experimental modeling of vicous inclusions in a circular high strain shear rig: Implications for the interpretation of shape fabrics and deformed enclaves. Journal of Geophysical Research 107, B10242, doi: 10.1029/2000JB000030.

Pouryazdan, M., Kaus, B.J.P., Rack, A., Ershov, A., Hahn, H., 2017. Mixing instabilities during shearing of metals. Nature Communications 8 , doi: 10.1038/s41467-017-01879-5.

Prakash, A., Lebensohn, R.A., 2009. Simulation of micromechanical behavior of polycrystals: finite elements versus fast Fourier transforms. Modelling and Simulation in Materials Science and Engineering 17, 064010. 
Qu, M., Jiang, D., Lu, L.X., 2016. An optimal scheme for numerical evaluation of Eshelby tensors and its implementation in a MATLAB package for simulating the motion of viscous ellipsoids in slow flows. Computers \& Geosciences 96, 98-108.

Ramsay and Huber, 1983. The techniques of modern structural geology, Volume 1: Strain Analysis. Academic Press, London.

Ramsay, L.J., 1967. Folding and Fracturing of Rocks. McGraw-Hill, New York.

Räss, L., Duretz, T., Podladchikov Y. Y., Schmalholz S. M., 2016. M2Di: Concise and efficient MATLAB 2-D Stokes solvers using the Finite Difference Method. Geochemistry, Geophysics and Geosystems 18, 755768.

Reuss, A., 1929. Berechnung der Fliessgrenzc von Mischkristallen auf Grund der Plastizitätsbedingung fiir Einkristalle. Z. Angew. Math. Mech. 9, 49-58.

Rosenberg, C.L., 2001. Deformation of partially molten granite: a review and comparison of experimental and natural case studies. International Journal of Earth Sciences 90, 60-76.

Roters, F., Eisenlohr, P., Bieler, T.R. and Raabe, D., 2011. Crystal plasticity finite element methods: in materials science and engineering. Wiley- $\mathrm{VCH}$, Weinheim.

Samanta, S.K., Bhattacharyya, G., 2003. Modes of detachment at the inclusion-matrix interface. Journal of Structural Geology 25, 1107-1120. Schneider C.A., Rasband W.S., Eliceiri K.W., 2012. NIH Image to ImageJ: 25 
years of image analysis. Nature Methods 9, 671-675.

Steinbach F., 2017. Numerical modelling of deformation and recrystallisation mechanics in ice and ice-air aggregates. Ph.D. thesis, Eberhard Karls University Tübingen.

Steinbach F., Bons, P.D., Griera A., Jansen, D., Llorens M.-G., Roessiger, J., Weikusat I., 2016. Strain localization and dynamics recrystallisation in the ice-air aggregate: A numerical study. The Cryosphere 10, 3071-3089.

Steinbach, F., Kuiper, E.-J.N., Eichler, J., Bons, P.D., Drury, M.R., Griera, A., Pennock, G.M., Weikusat, I., 2017. The relevance of grain dissection for grain size reduction in polar ice: insights from numerical models and ice core microstructure analysis. Frontiers in Earth Science 5, doi: 10.3389/feart.2017.00066.

Takeda, Y.T., Griera, A., 2006. Rheological and kinematical responses to flow of two-phase rocks. Tectonophysics 427, 95-113.

Tikoff, B., Teyssier, C., 1994. Strain and fabric analysis based on porphyrocalst interaction. Journal of Structural Geology 16, 477-491.

Trap, P., Faure, M., Lin, W., Le Breton, N. and Monié, P., 2012. Paleoproterozoic tectonic evolution of the Trans-North China Orogen: toward a comprehensive model. Precambrian Research 222, 191-211. Treagus, S.H. 1999. Are viscosity ratios of rocks measurable from cleavage refraction? Journal of Structural Geology 21, 895-901.

Treagus, S.H., 2002. Modelling the bulk viscosity of two-phase mixtures in 
terms of clast shape. Journal of Structural Geology 24, 57-76.

Treagus, S.H., 2003. Viscous anisotropy of two-phase composites, and application to rocks and structures. Tectonophysics 372, 121-133.

Treagus, S.H., Lan, L., 2003. Simple shear of deformable square objects. Journal of Structural Geology 25, 1993-2003.

Treagus, S.H., Lan, L., 2004. Deformation of square objects and boudins. Journal of Structural Geology 26, 1361-1376.

Treagus, S.H., Treagus, J.E., 2001. Effects of object ellipticity on strain, and implications for clast-matrix rocks. Journal of Structural Geology 23, 601608.

Treagus, S.H., Treagus, J.E., 2002. Studies of strain and rheology of conglomerates. Journal of Structural Geology 24, 1541-1567.

Vitale, S., Mazzoli, S., 2005. Influence of object concentration on finite strain and effective viscosity contrast: insights from naturally deformed packstones. Journal of Structural Geology 27, 2135-2149.

Voigt,W., 1928. I.ehrbuch der Kristallphysik. Teubner, Leibzig.

Weijermars, R., 1993. Pulsating strains. Tectonophysics 220, 51-67.

Yin, A., Harrison, T.M., Murphy, M.A., Grove, M., Nie, S., Ryerson, F.J., Wang, X.F., Chen, Z.L., 1999. Tertiary deformation history of southeastern and southwestern Tibet during the Indo-Asian collision. Geological Society of America Bulletin 111, 1644-1664.

Zhang, J., Zhao, G., Li, S., Sun, M., Chan, L. S., Shen, W., Liu, S., 2012. 
Structural pattern of the Wutai Complex and its constraints on the tectonic framework of the Trans-North China Orogen. Precambrian Research 222, 212-229.

Zhao, G.C., Sun, M., Wilde, S.A., Li, S.Z., 2005. Late Archean to

Paleoproterzoic evolution of the North China Craton: key issues revisited. Precambrian Research 136, 177-202.

Zhao, G.C., Wilde, S.A., Cawood, P.A., Sun, M., 2001. Archean blocks and their boundaries in the North China Craton: lithological, geochemical, structural and $\mathrm{P}-\mathrm{T}$ path constraints and tectonic evolution. Precambrian Research 107, 45-73.

\section{Figure captions}

Fig. 1. Data structure. (a) The square unit-cell contains circular pebbles (black) embedded in a homogeneous matrix (grey) composed of a set of flynns (defined by white solid lines). (b) and (c) Flynns are defined by bnodes and define the pebble-matrix boundaries, as well as sub-regions. (d) The model is repositioned into the initial square unit cell after each step of dextral simpleshear deformation. (e) Deformation is assumed to take place by glide of dislocations along the slip systems of a hexagonal mineral. (f) Unconnected nodes (unodes) are superimposed on flynns and used for storing physical properties and state variables. (c) and (f) show the difference of region 
boundaries defined by flynns and unodes that are used for the VPFFT code.

Fig. 2. Results of simulations with different $R \eta$-settings with a stress exponent of $n=1$ (a) and $n=3$ (b) for simple-shear deformation (top to the right) up to a shear strain of $\gamma=10$. Pebbles are black, matrix light grey and flynn boundaries white. Initial structures of conglomerates with pebble concentrations of $C=10 \%, 30 \%$ and $45 \%$ are shown as the first column of (a). The pebble behaviour is labelled as passive (P), deformable (D) or rigid (R). Movies 1-5 can be found in Appendix A.

Fig. 3. Mean $R_{f} \phi$ graph showing the trajectories of the mean pebble shape $\left(R_{f}\right)$ and long axis orientation $(\phi)$ for the different simulations as a function of strain. All the data displayed correspond to the arithmetic mean of the $R_{f}$ or $\phi$ of all individual pebbles in a model. Sub-vertical dashed lines indicate finite strain contours. Dark blue dashed lines separate passive, deformable and rigid pebble behaviour.

Fig. 4. Normalised mean rotation (vorticity) of all individual pebbles (with one standard deviation error bars) at different pebble concentrations of $C=10 \%$, $30 \%$ and $45 \%$ and viscosity ratio of $R \eta=10$ in power-law $(n=3)$ viscous rheology, for a strain increment of $\Delta \gamma=0.5$. Normalised mean rotation is defined as the ratio between mean ration angle in the simulation and the ideal Jeffery's 
(1922) rotation of $14.3^{\circ}$ for $\Delta y=0.5$. Each mean rotation angle with standard deviation is calculated from all rotation data at finite strains of $\gamma=3.5-4,4-4.5$, 4.5-5, 5-5.5 and 5.5-6 in simulations $10 \%_{R \eta 10}^{n 3}, 30 \%_{R \eta 10}^{n 3}$ and $45 \%_{R \eta 10}^{n 3}$. The rotation angle of one cluster is selected from the simulation $30 \% R \eta 10$ for $\Delta \gamma=0.5(\gamma=4-4.5)$.

Fig. 5. Maps of the Von Mises strain-rate field normalised to the bulk Von Mises strain rate at different viscosity ratios $(R \eta)($ column I - III $)$ and vorticity (for $\Delta \gamma=0.02)$ at different viscosity ratios $(R \eta)$ (column IV-VI) for (a) power-law $(n=3)$ and $(\mathbf{b})$ linear $(n=1)$ viscous rheology at finite strain of 10 . The bulk sense of shear is top to right.

Fig. 6. Evolution of rigid clusters in the simulation $30 \%_{R \eta 10}^{n 3}$ (Appendix A, Movie 4). Pebble (white and coloured) and matrix (black) distribution is shown at shear strains of (a) $\gamma=4.5$, (d) at $\gamma=6.0$ and (g) $\gamma=6$.6. Pebbles belonging to a cluster are coloured. Incremental strain $\left(R_{S}, \mathbf{b}, \mathbf{e}, \mathbf{h}\right)$ and vorticity $(W ; \mathbf{c}, \mathbf{f}, \mathbf{i})$ distributions are shown for the preceding strain increment of $\Delta \gamma=0.2$. Three pebbles are labelled A to C. At $\gamma=4.5$ they form a cluster, which has disintegrated at $\gamma=6$. Pebbles A and B form a cluster again at $\gamma=6$.6. The sense of shear is top to the right.

Fig.7. Evolution of deformable clusters in simulation $30 \%_{R \eta^{2}}^{n 3}$ (Appendix A, 
Movie 3). Pebble and matrix (black) distribution is shown at (a) $\gamma=4.5$, (d) at $\gamma=7$ and $\mathbf{( g )} \gamma=8$. Pebbles belonging to a cluster are coloured. Incremental strain $\left(R_{s}, \mathbf{b}, \mathbf{e}, \mathbf{h}\right)$ and vorticity $(W ; \mathbf{c}, \mathbf{f}, \mathbf{i})$ distributions are shown for the preceding strain increment of $\Delta \gamma=1$. Three clusters are labelled $\mathrm{A}$ to $\mathrm{C}$. The life span of these clusters with increasing finite strain is shown in (j). The sense of shear is top to the right.

Fig. 8. Mean $R_{f} \phi$ plot for deformed conglomerates with different viscosity ratios $(R \eta)$ and concentrations $(C)$. Perfectly passive and rigid behaviours are shown as solid red lines. The solid pink line separates the pulsating and permanently stretching deformation behaviour. Dark blue dashed lines separate effectively passive, deformable and effectively rigid behaviours. Subvertical dashed lines are contours of the bulk finite strain $(\gamma)$.

Fig. 9. (a) Variation of mean aspect ratios $\left(R_{f}\right)$ with increasing finite strain $\left(R_{s}\right)$ for simulations with different pebble concentrations and $R \eta$ for both linear ( $n=1$, red to orange) and power-law ( $n=3$, blue to green) rheologies. Our simulations are represented by the solid lines with data points and Gay's (1968) prediction as dashed lines. (b) Comparison of viscosity ratios $(R \eta)$ and calculated viscosity ratios $\left(R \eta_{\text {Gay }}\right)$ using Eq. (4). Most $n=1$ data lie below the black $R \eta=R \eta_{\text {Gay }}$-line, indicating that Eq. (4) tends to underestimate the viscosity contrast, especially at higher pebble concentrations. 
Fig. 10. Deformed conglomerates in North China Craton compared with our simulation. (a) Tectonic subdivision of the North China Craton (modified after Zhao et al., 2005). TNCO is Trans-North China Orogen. (b) Simplified geological map of the Yangjiaogou area and location of the outcrop with deformed Hutuo Group conglomerates. (c) Rolling structure and a boudinaged quartz vein indicating top-to-the-left sinistral simple shear. The ratio between final and initial length of boudinage quartz vein is estimated at ca. 2.3. The diameter of the 1 dollar-cent coin is $19 \mathrm{~mm}$. (d) and (e) Interactions between pebbles in outcrop compared with our simulation $10 \%{ }_{v r 5}^{n 1}$ at a finite strain of eight.

Fig. 11. Mean $R_{f} \phi$ plot for comparing the outcrop data (with one standard deviation error bars) of deformed conglomerates in the Yangjiaogou area compared with our simulations at different finite strains $(\gamma)$ plotted on the graph of Fig. 8. 
Table 1. Settings for the simulations presented here.

\begin{tabular}{|c|c|c|c|c|}
\hline Experiment & $\begin{array}{c}\text { Pebble } \\
\text { concentration (C) }\end{array}$ & $\begin{array}{l}\text { Stress exponent } \\
\text { (n) }\end{array}$ & $s$ & $\begin{array}{c}\text { Supplementary } \\
\text { movie }\end{array}$ \\
\hline $10 \%_{R \eta 2}^{n 1}$ & $10 \%$ & 1 & 2 & \\
\hline $10 \%_{R \eta 5}^{n 1}$ & $10 \%$ & 1 & 5 & Movie 1 \\
\hline $10 \%_{R \eta 15}^{n 1}$ & $10 \%$ & 1 & 15 & \\
\hline $10 \%{ }_{R \eta 4}^{n 1}$ & $10 \%$ & 1 & 45 & \\
\hline $30 \%_{R \eta 2}^{n 1}$ & $30 \%$ & 1 & 2 & \\
\hline $30 \%{ }_{R \eta 5}^{n 1}$ & $30 \%$ & 1 & 5 & \\
\hline $30 \% \stackrel{n 1}{n \eta 15}$ & $30 \%$ & 1 & 15 & \\
\hline $30 \%{ }_{R \eta 45}^{n 1}$ & $30 \%$ & 1 & 45 & \\
\hline $45 \%_{R \eta 2}^{n 1}$ & $45 \%$ & 1 & 2 & \\
\hline $45 \%_{R \eta 5}^{n 1}$ & $45 \%$ & 1 & 5 & Movie 2 \\
\hline $45 \%{ }_{R \eta 1}^{n 1}$ & $45 \%$ & 1 & 15 & \\
\hline $45 \%{ }_{R \eta 45}^{n 1}$ & $45 \%$ & 1 & 45 & \\
\hline $10 \%_{R \eta 2}^{n 3}$ & $10 \%$ & 3 & 2 & \\
\hline $10 \%_{R \eta 5}^{n 3}$ & $10 \%$ & 3 & 5 & \\
\hline $10 \%{ }_{R \eta 10}^{n 3}$ & $10 \%$ & 3 & 10 & \\
\hline $30 \%_{R \eta 2}^{n 3}$ & $30 \%$ & 3 & 2 & Movie 3 \\
\hline $30 \%_{R \eta 5}^{n 3}$ & $30 \%$ & 3 & 5 & \\
\hline $30 \%{ }_{R \eta 10}^{n 3}$ & $30 \%$ & 3 & 10 & Movie 4 \\
\hline $45 \%{ }_{R \eta 2}^{n 3}$ & $45 \%$ & 3 & 2 & Movie 5 \\
\hline $45 \%_{R \eta 5}^{n 3}$ & $45 \%$ & 3 & 5 & \\
\hline $45 \%{ }_{R \eta 10}^{n 3}$ & $45 \%$ & 3 & 10 & \\
\hline
\end{tabular}




\section{Appendix A}

Movies of selected simulations, showing pebble and strain rate distributions.

Movie 1: $10 \% \frac{n 1}{R \eta 5}$, Movie 2: $45 \%_{R \eta 5}^{n 1}$, Movie 3: $30 \%_{R \eta 2}^{n 3}$, Movie 4: $30 \%_{R \eta 10}^{n 3}$,

Movie 4: $45 \%{ }_{R \eta 2}^{n 3}$.

\section{Appendix B}

The expression for the deformation of a linear marker under simple and pure shear in 2-D plane is given by Ramsay and Huber (1987; pp.283-286).

Consider a line of unit length that joins coordinates $(0,0)$ and $(x, y)$ and which has an angle $\alpha$ with the $x$-direction. After deformation, $(x, y)$ is positioned at $\left(x^{\prime}\right.$, $\left.y^{\prime}\right)$ and the line now has an angle $\alpha^{\prime}$ with the axis and its length is now $1+e$. We assume homogeneous finite strain, described with:

$x^{\prime}=a x+b y$

$y^{\prime}=c x+d y$

where $a, b, c$ and $d$ are the elements of the position gradient tensor. For simple shear, the tensor is

$\left|\begin{array}{ll}a & b \\ c & d\end{array}\right|=\left|\begin{array}{ll}1 & \gamma \\ 0 & 1\end{array}\right|$

The equation for the reciprocal quadratic extension $\left(\lambda^{\prime}=1 /(1+e)^{2}\right)$ is given as: 


$$
\lambda^{\prime}=\frac{\frac{1}{2}\left(d^{2}+c^{2}-a^{2}-b^{2}\right) \cos 2 \alpha^{\prime}-(a c-b d) \sin 2 \alpha^{\prime}+\frac{1}{2}\left(a^{2}+b^{2}+c^{2}+d^{2}\right)}{(a d-b c)^{2}}
$$

The relationship between $\alpha$ and $\alpha$ is:

$\tan \alpha=\frac{c-a \tan \alpha^{\prime}}{b \tan \alpha^{\prime}-d}$

The ratio between stretching and initial length $(e)$ of the boudinage quartz vein in Yangjiaogou area (Fig. 10c) is estimated at ca. 2.3 and the angle $\left(\alpha^{\prime}\right)$ between boudinage quartz vein and shear plane is ca. $9.1^{\circ}$. Inserting these values into Eqs. (B2) and (B3) gives two solutions: $\gamma=3.7$ and $\alpha=22^{\circ}$ or $\gamma=8.7$ and $\alpha=-22^{\circ}$. 


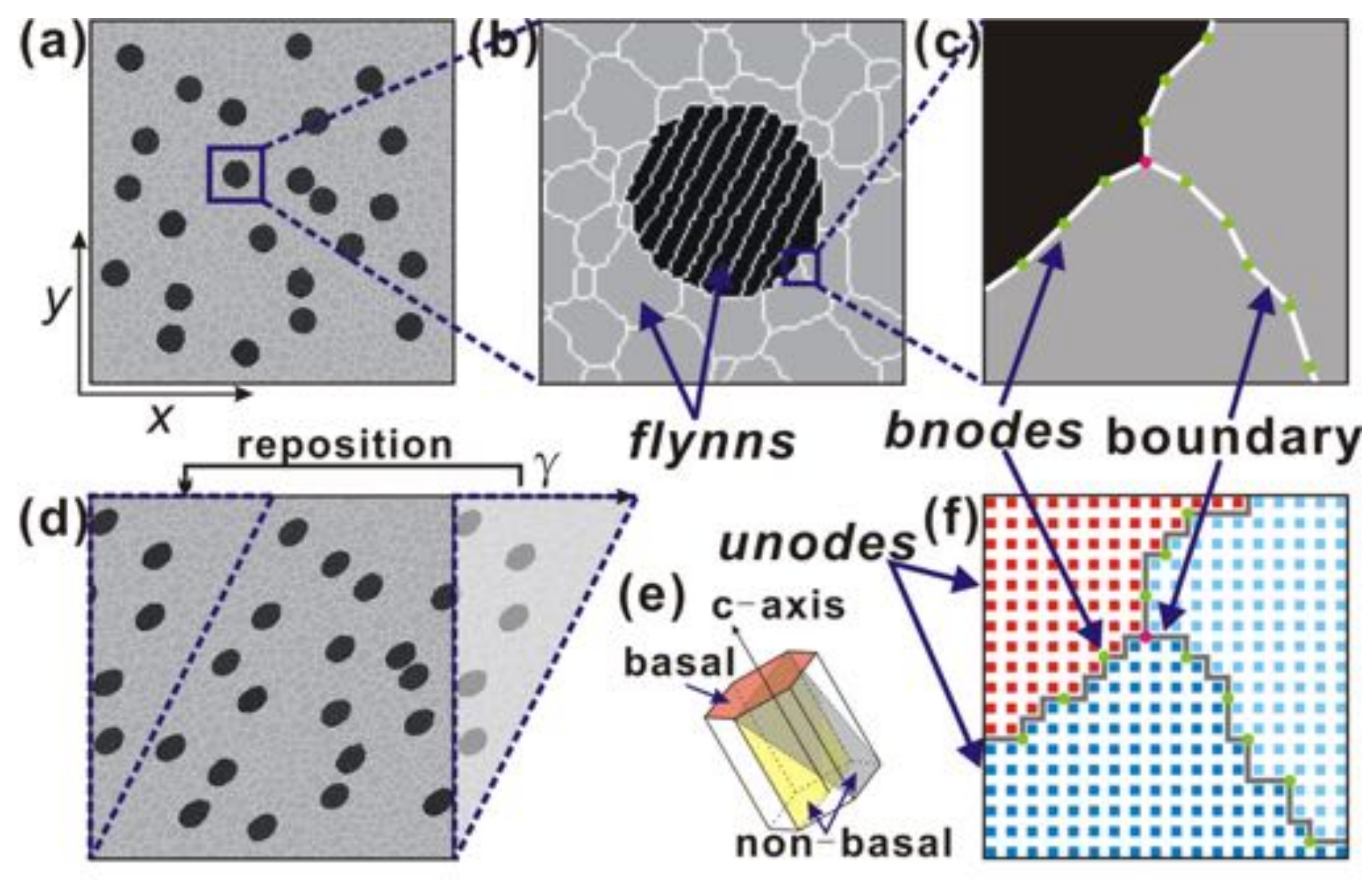

Fig. 1 


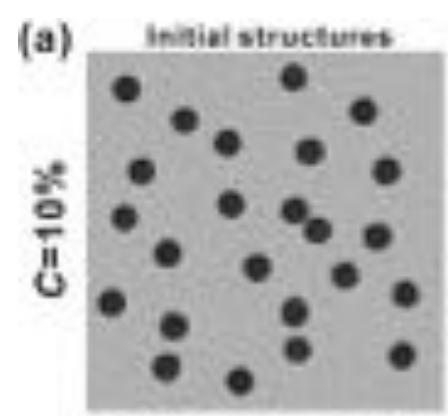

c 6 웅 es.

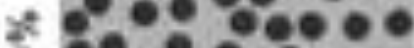

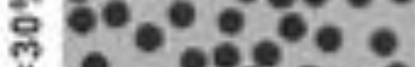
If b e -

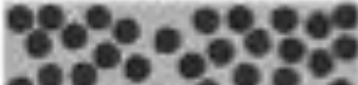

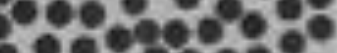
a ceregerese $\checkmark$ osere o 앙하웅

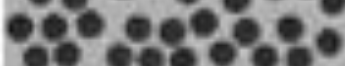

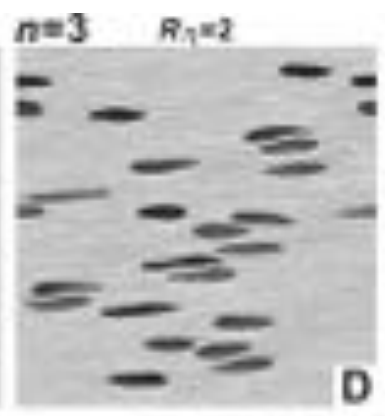

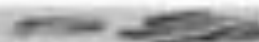

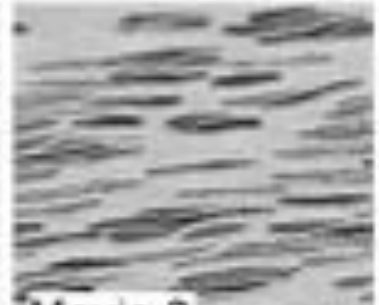

Movie $3=-0$

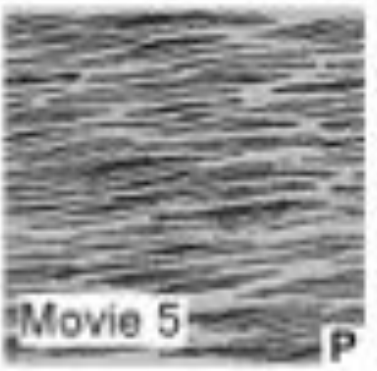

$n_{y}=5$

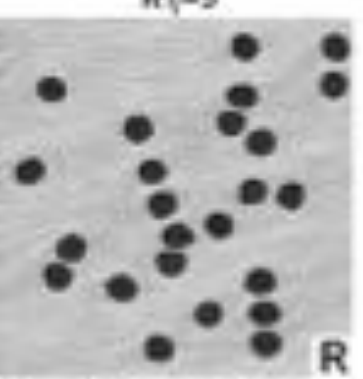

Pnoto

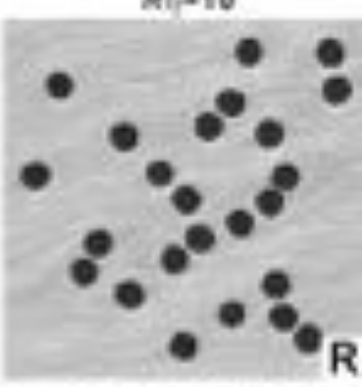

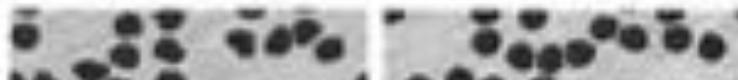
1s.5:

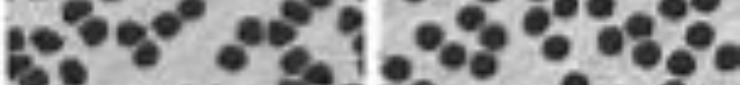

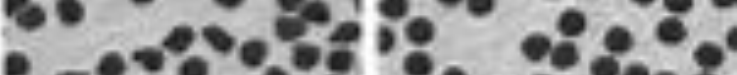
8 -

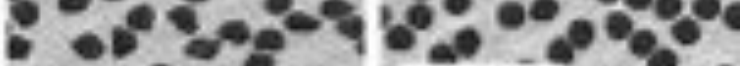
- og 2 Rovie 4 ger

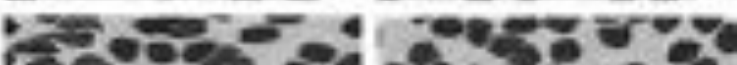

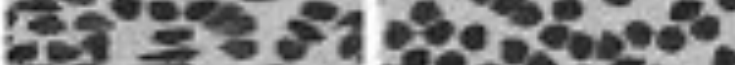

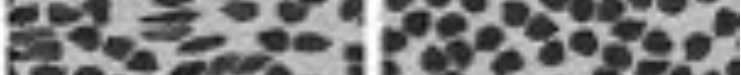

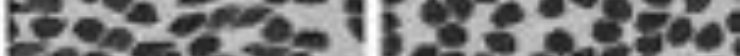

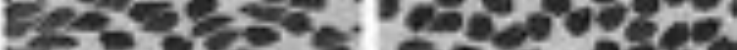

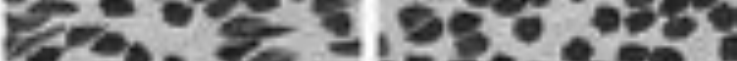

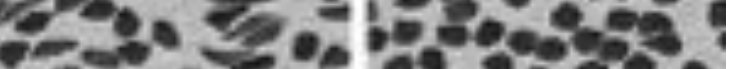
Movie 5 -

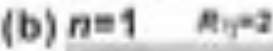

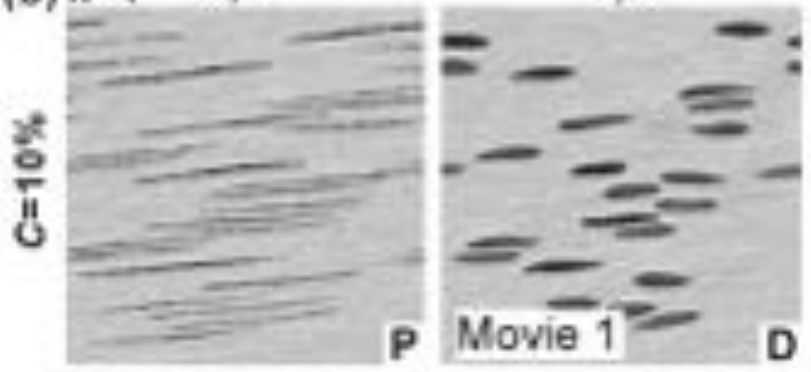
Riyes Rus 15 Aryats
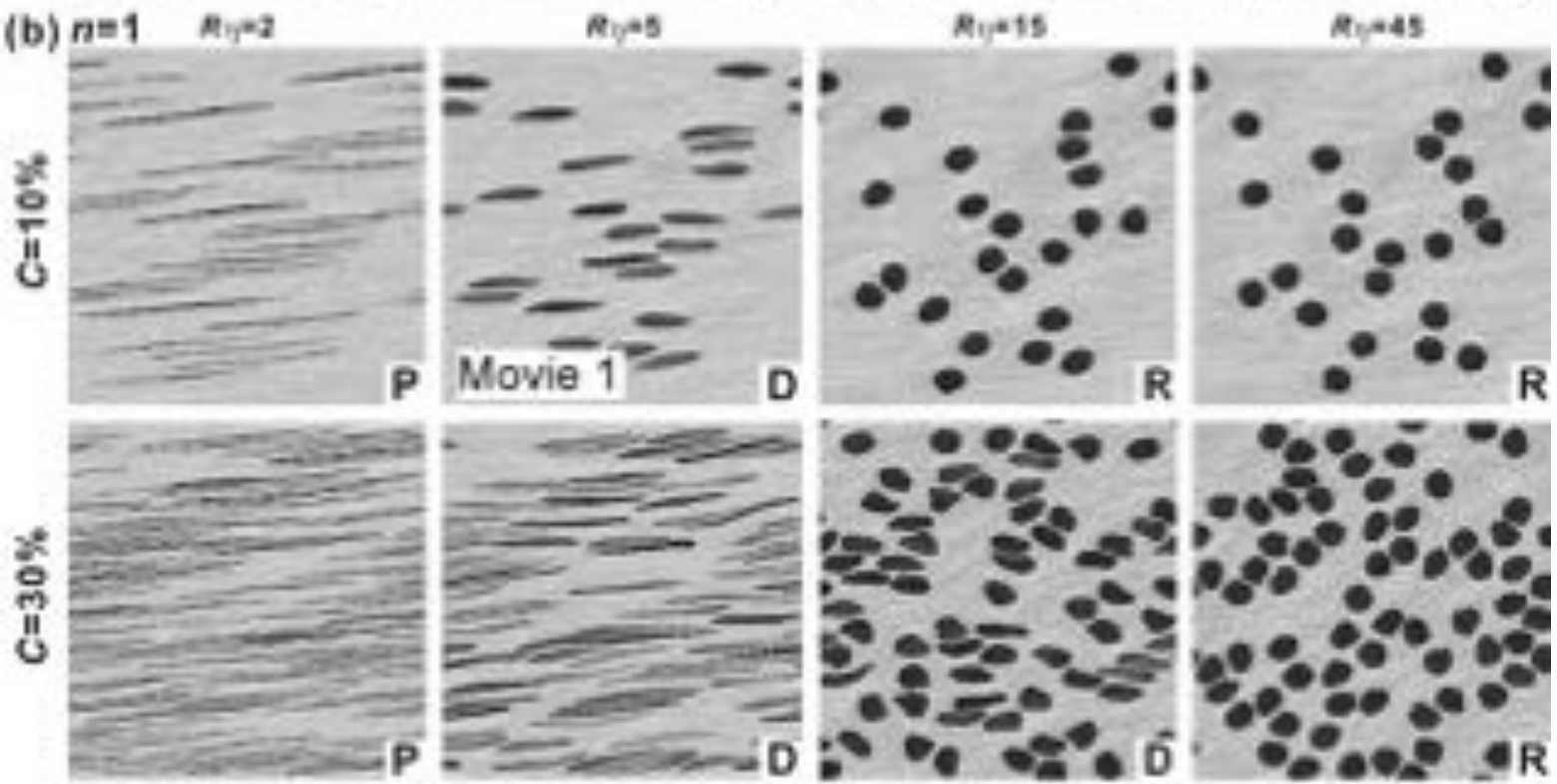

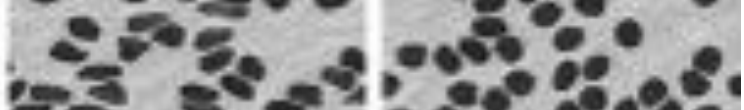

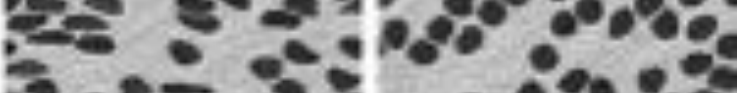

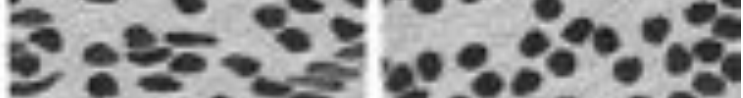

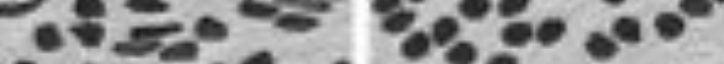
-
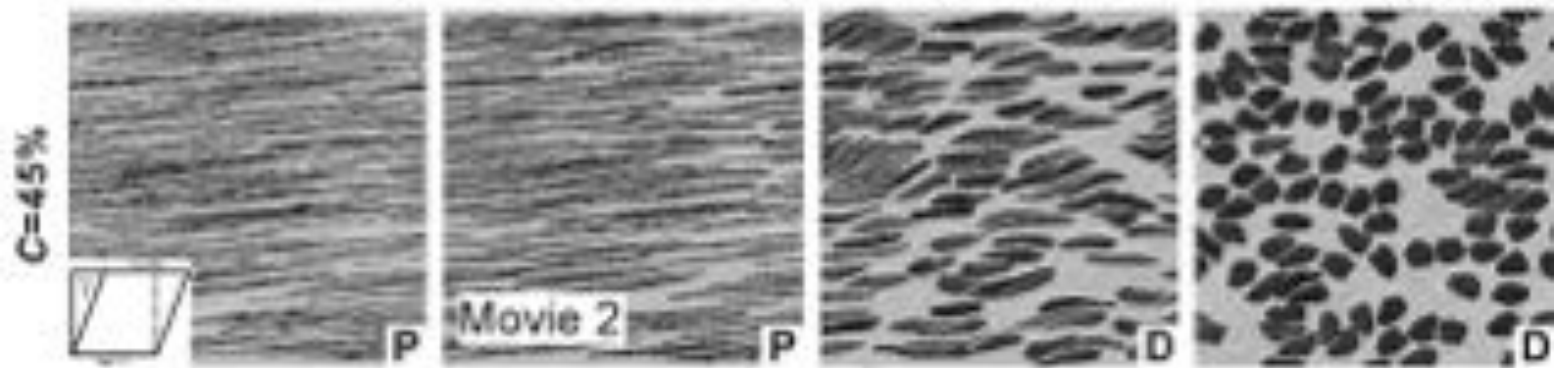

Fig. 2 


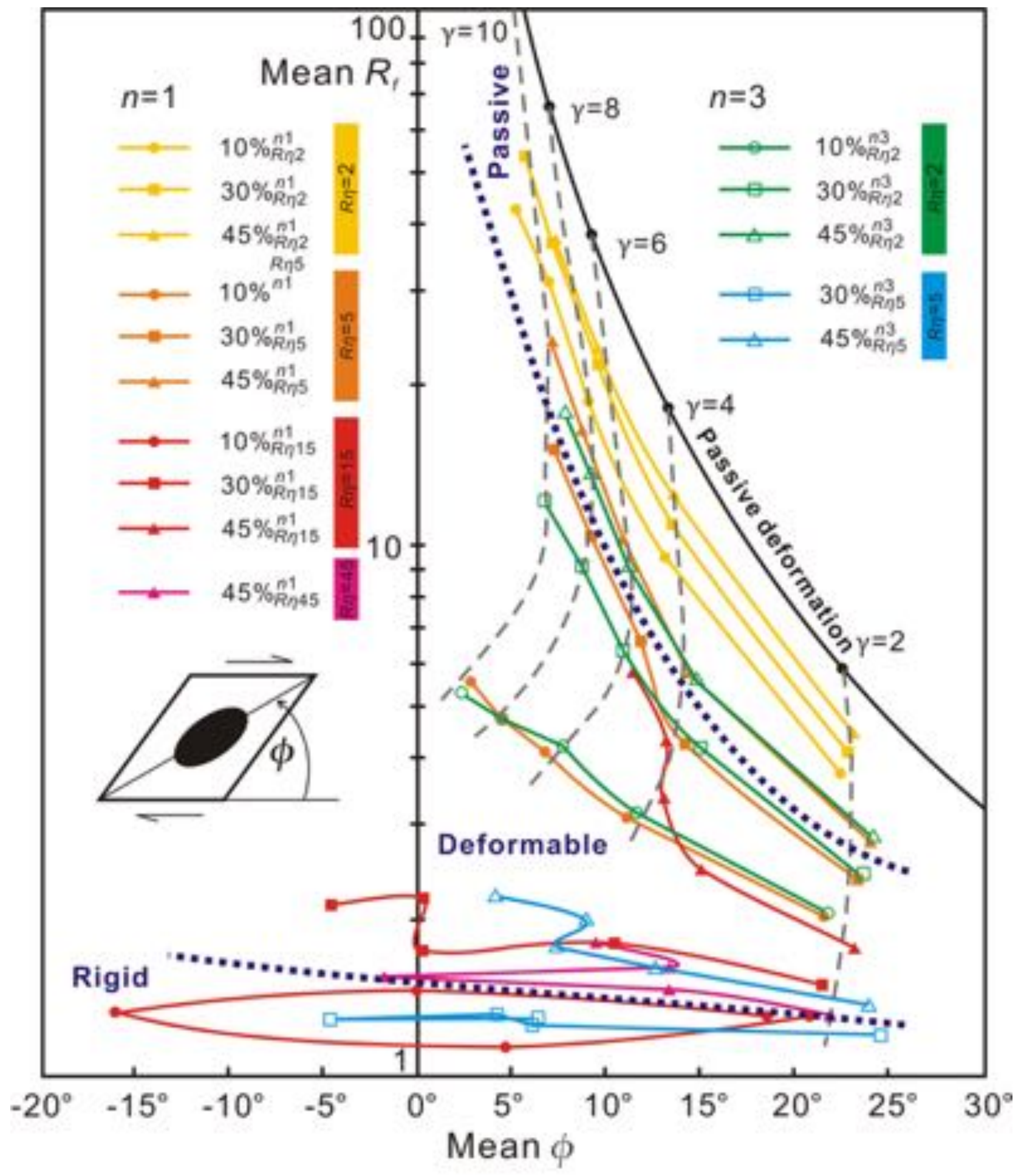

Fig. 3 


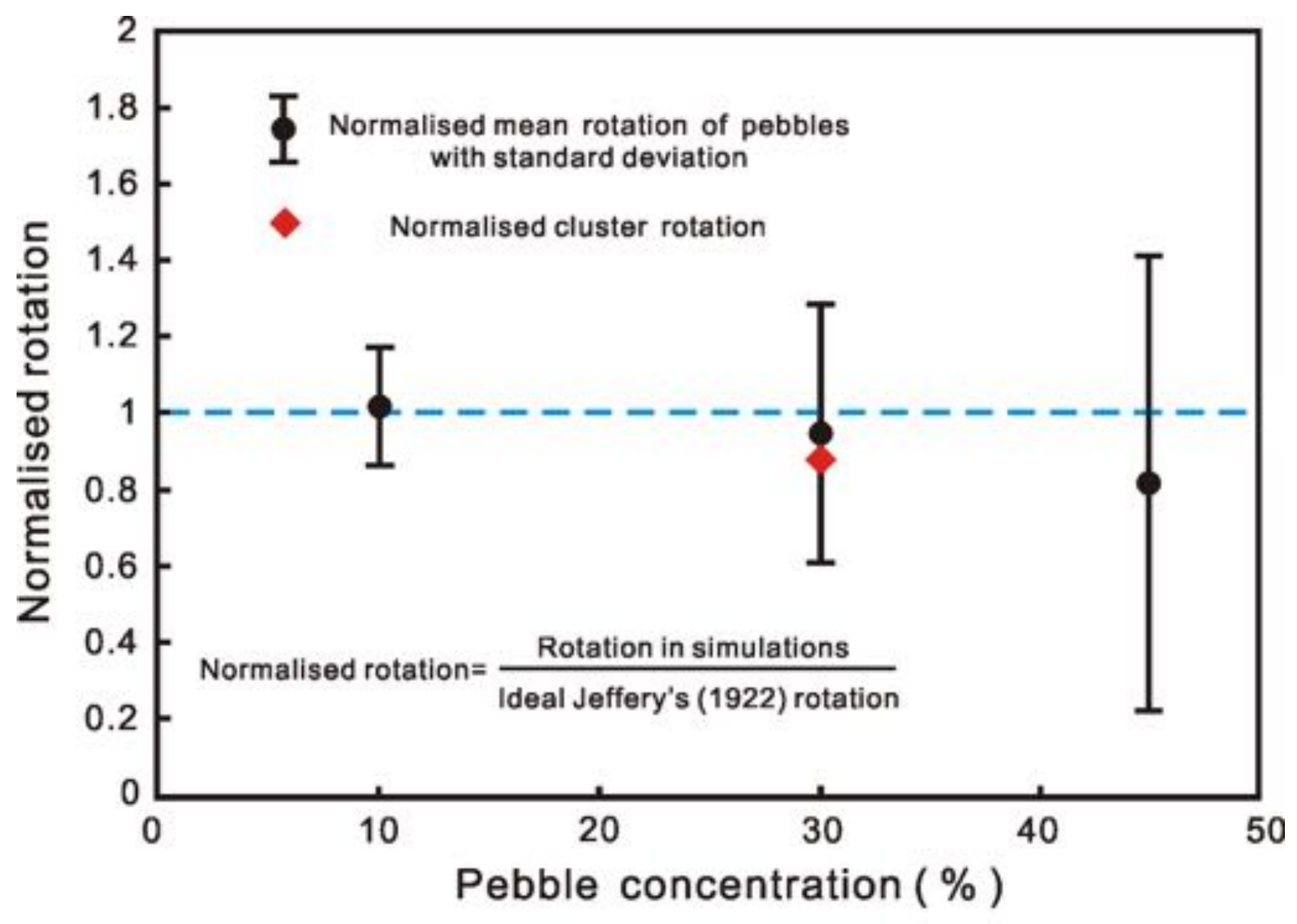

Fig. 4 
Normalized strain fate

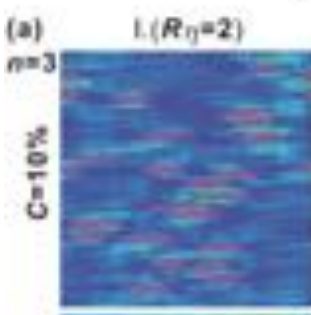

II. $\left(R_{\mathrm{g}}=5\right)$

III. $(R,=10)$

Vorticity ( $W$ )
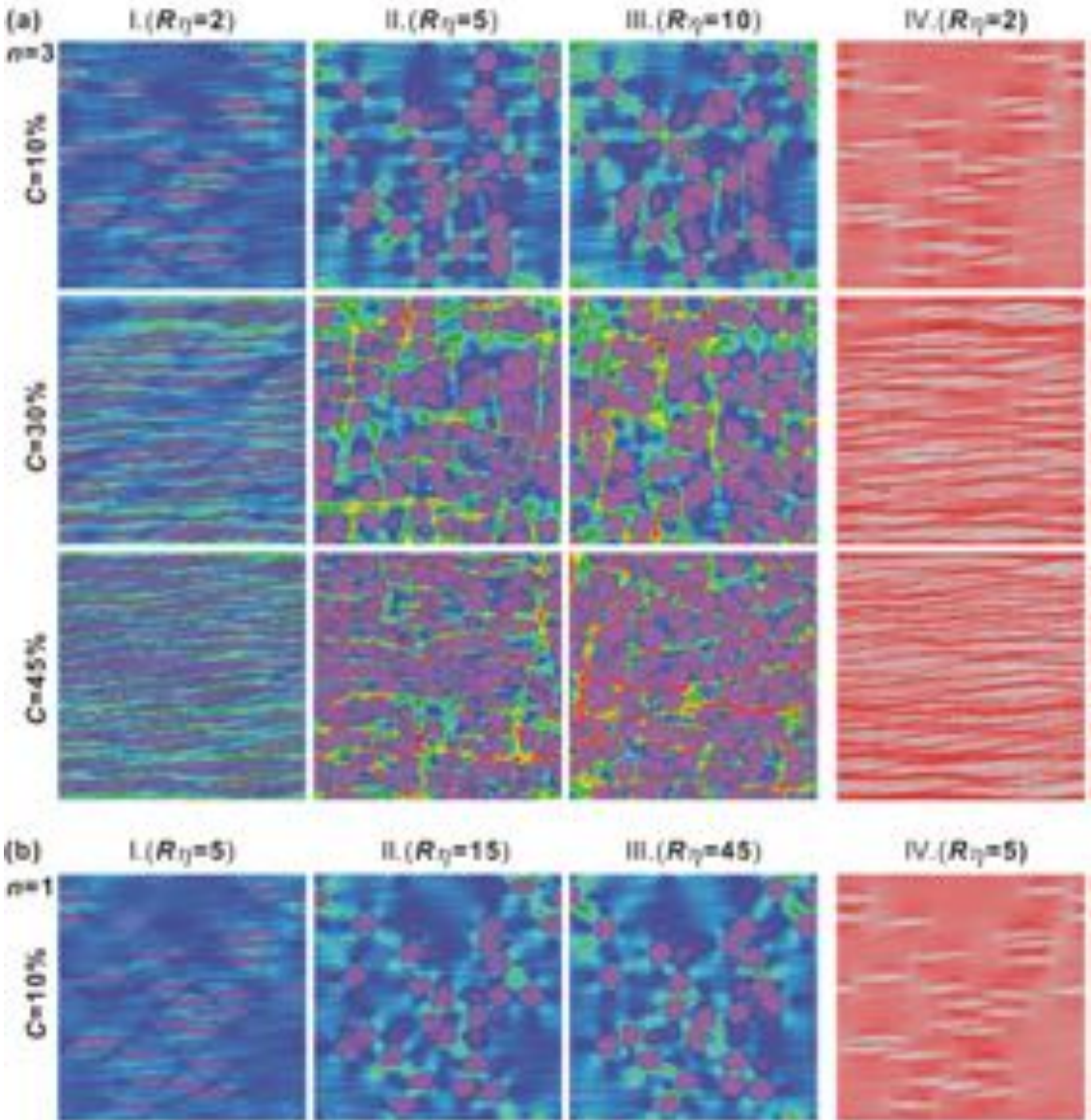

Y. $(R=5)$

V $\left(R_{\eta}=10\right)$
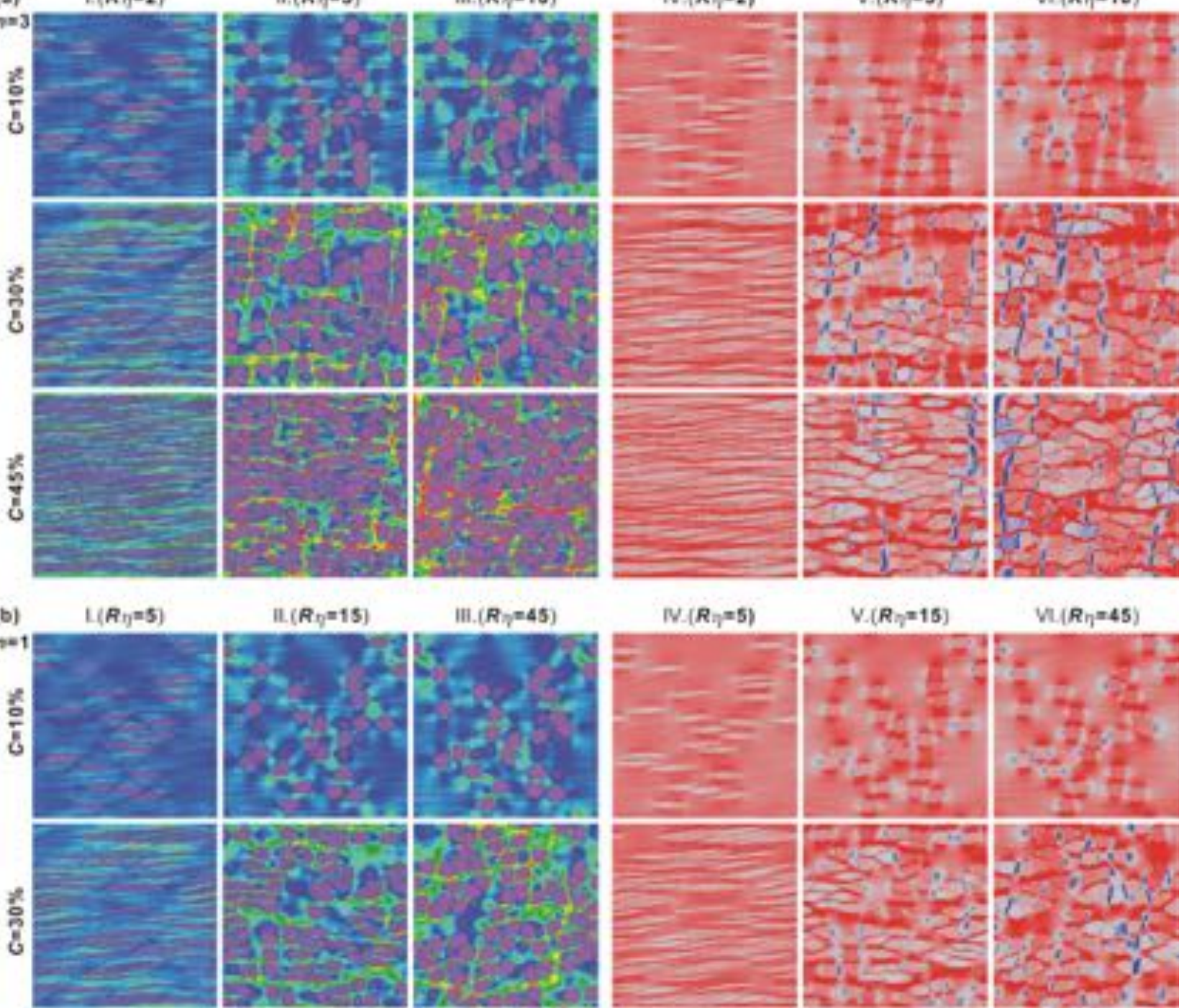

Y. $\left\{R_{\eta}=45\right)$
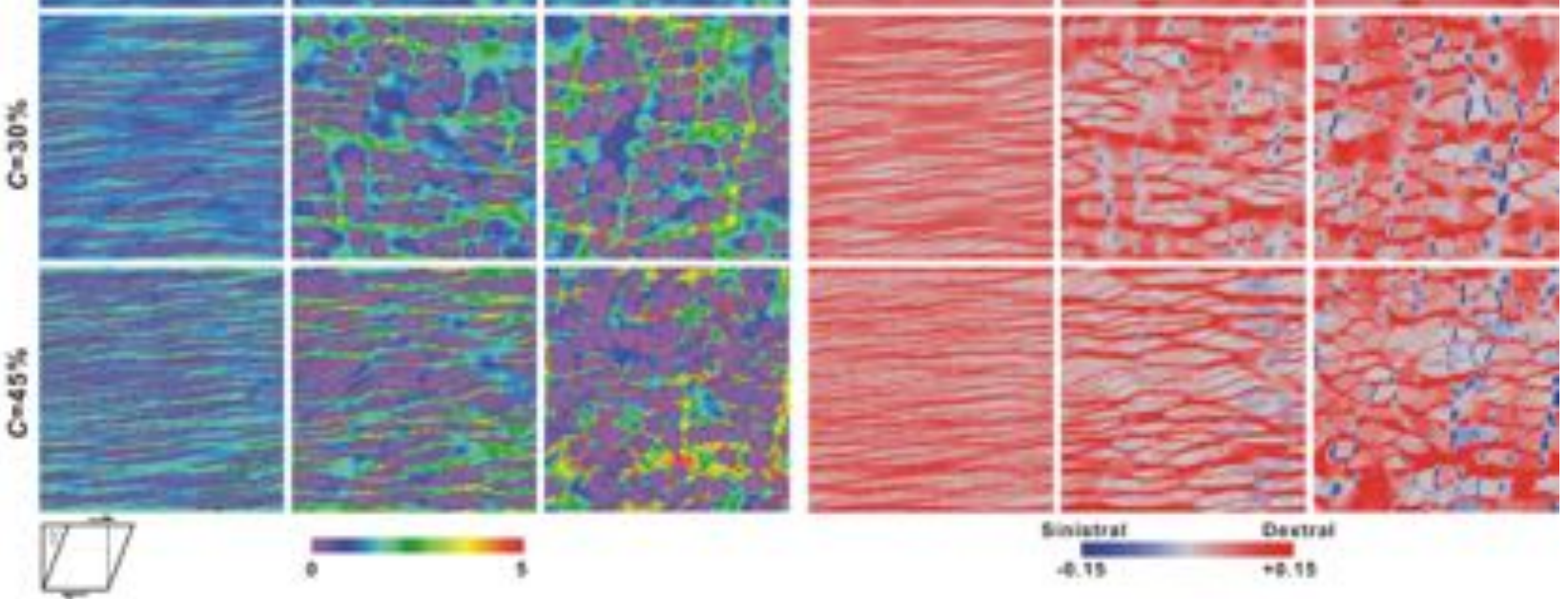

Fig. 5 


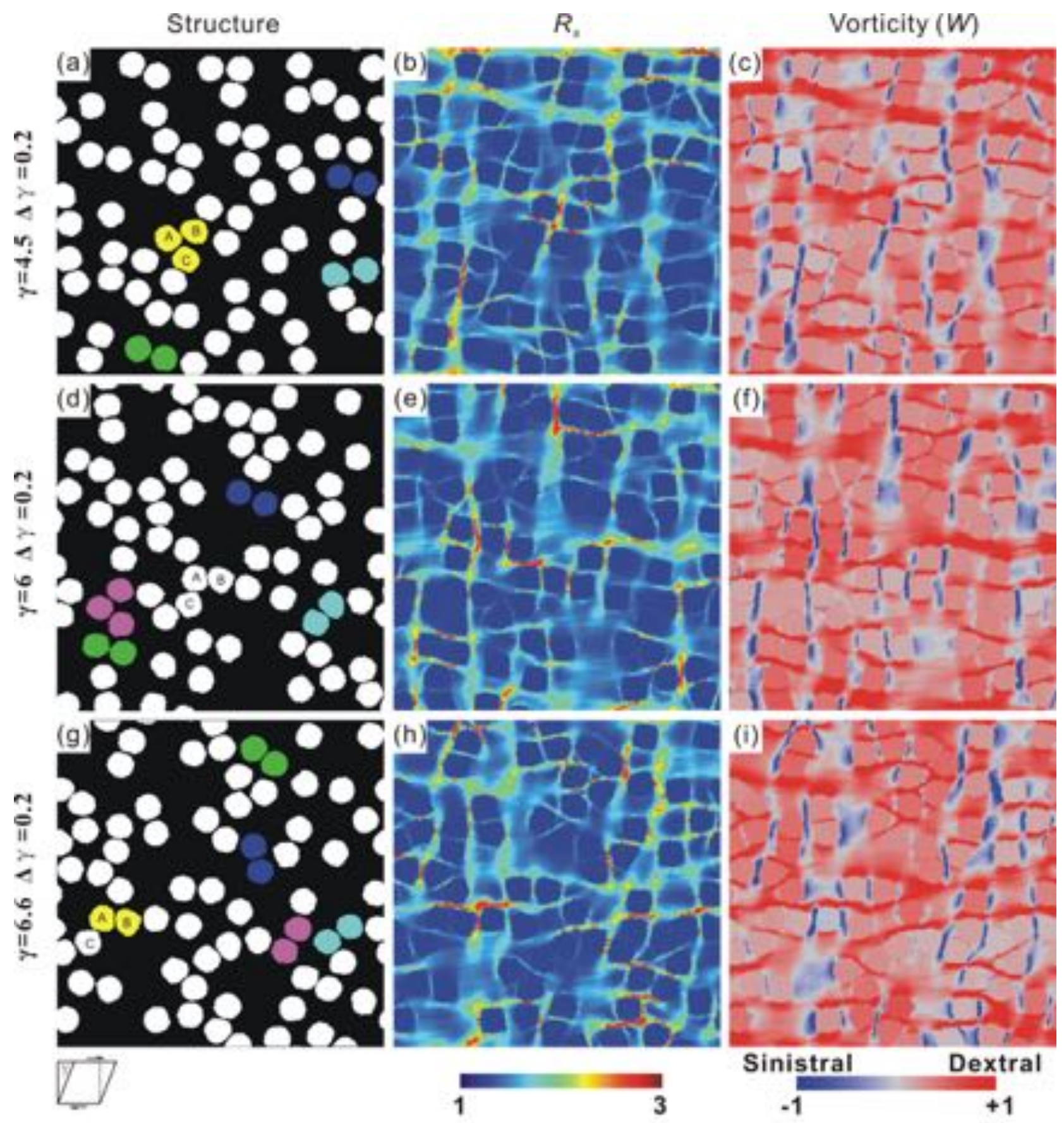

Fig. 6 


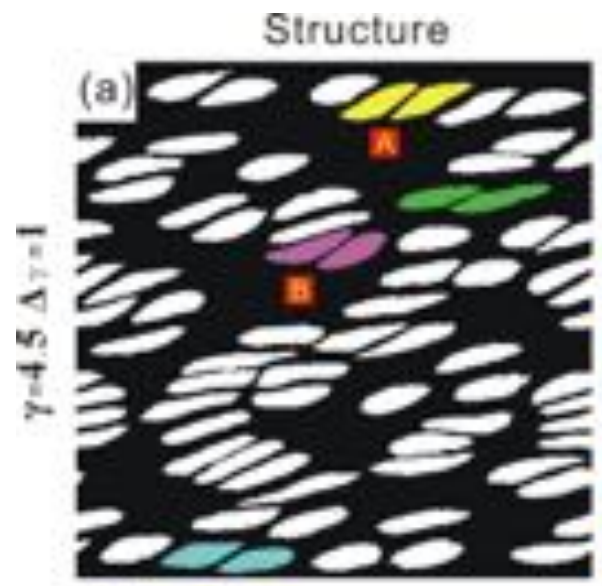

$R_{\text {s }}$
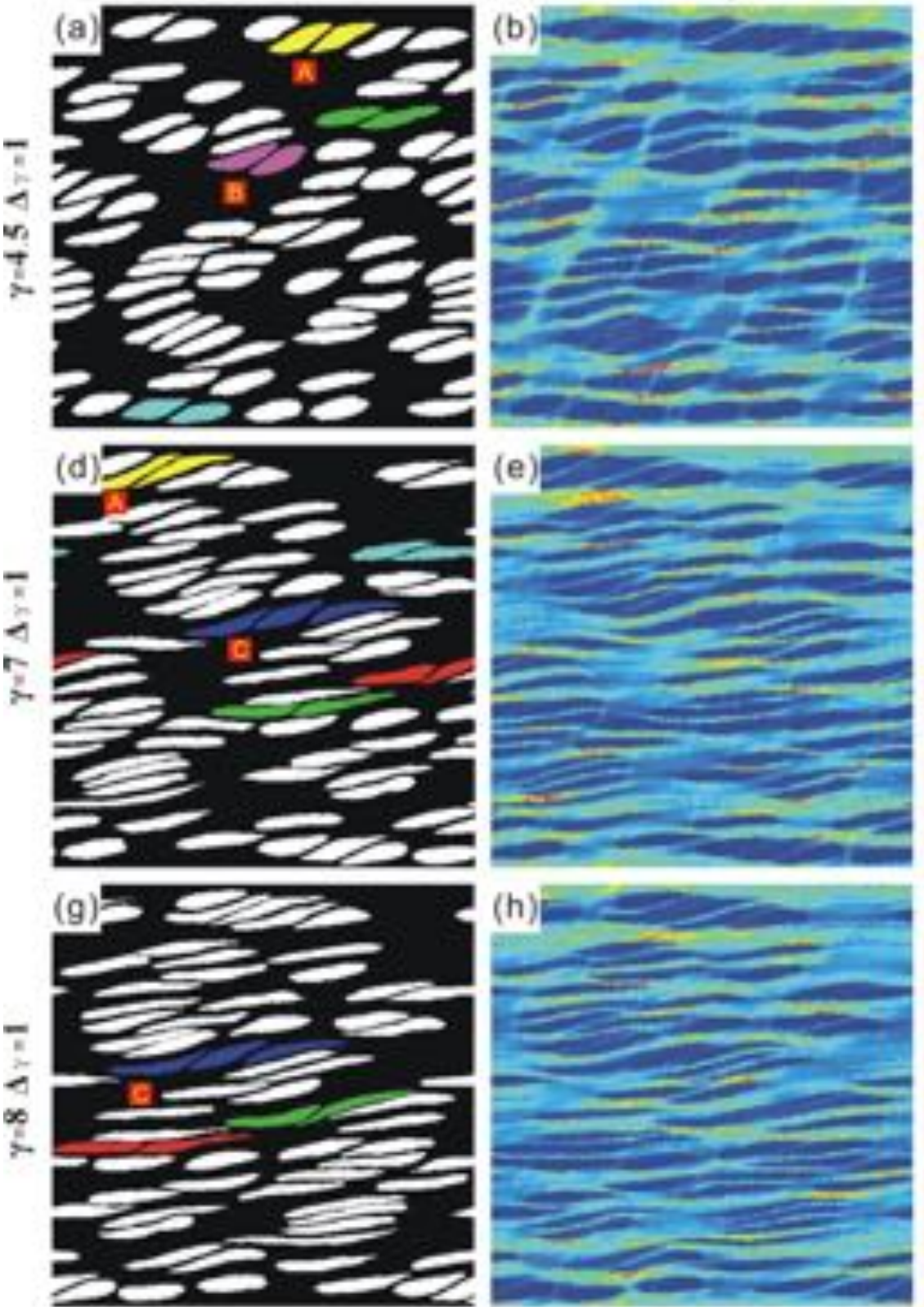
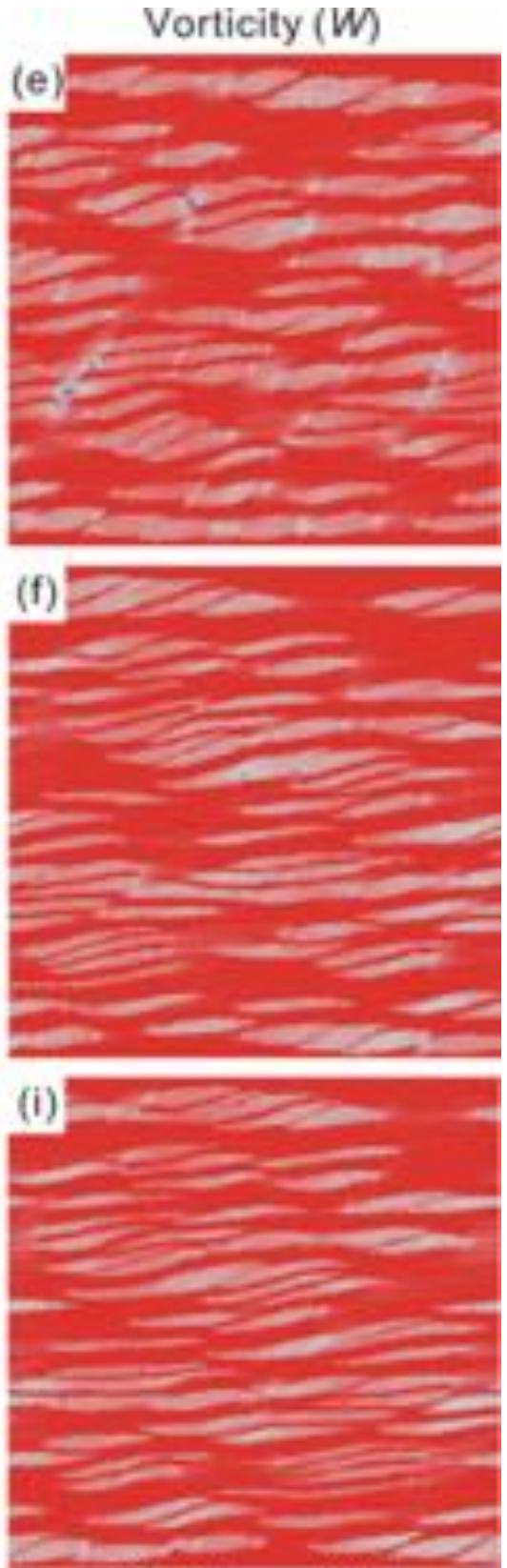

Sinistral Dextra!

.2
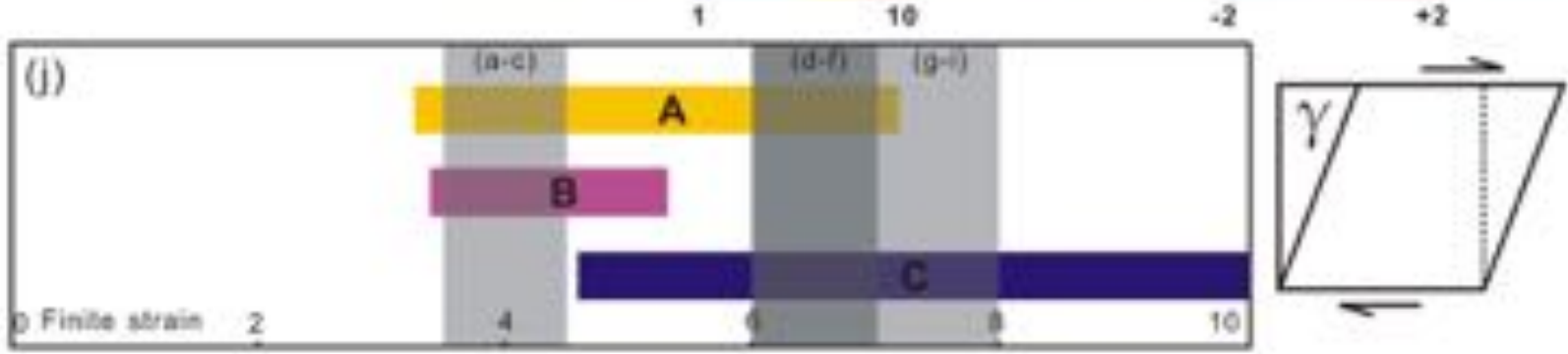

Fig. 7 


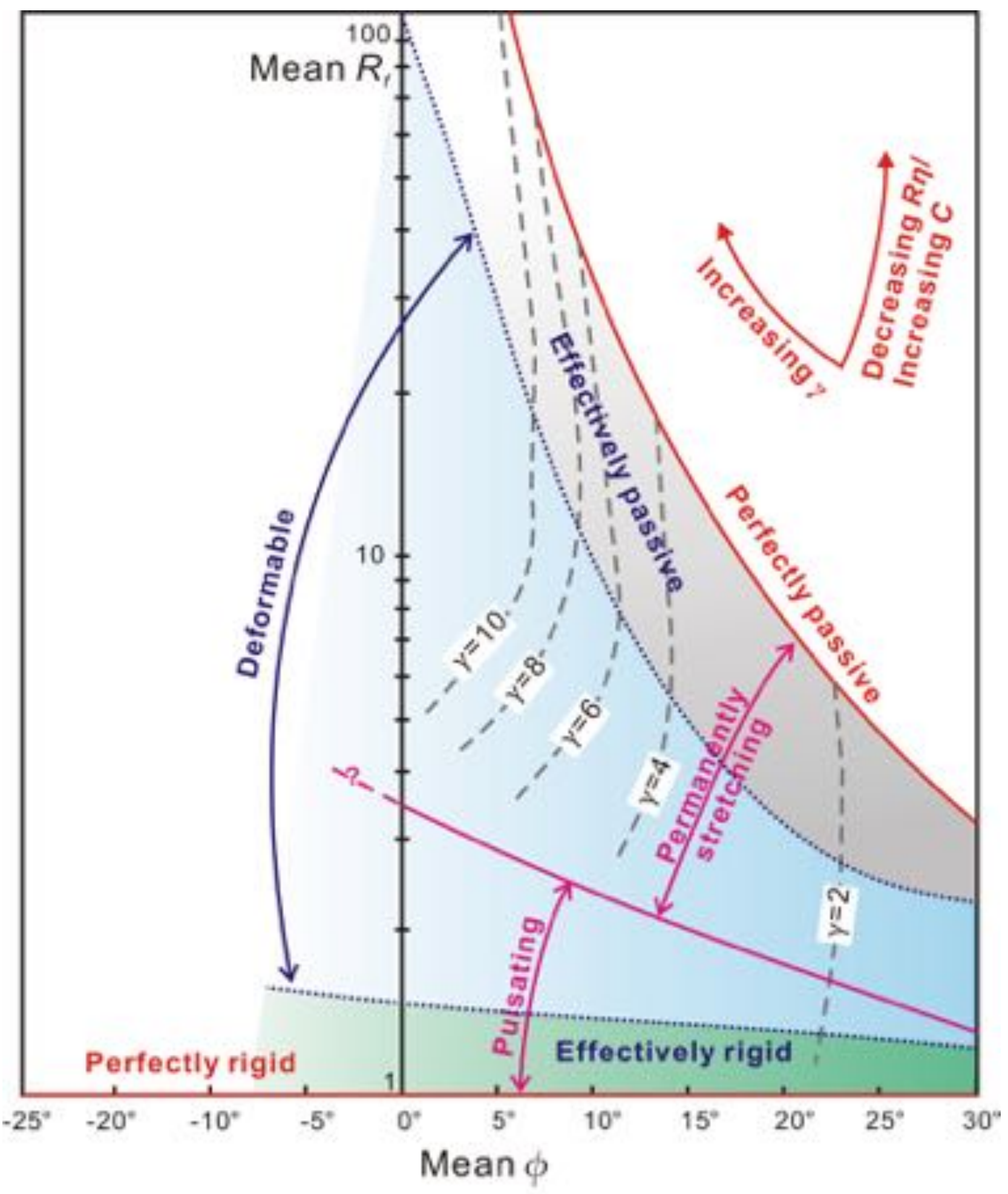

Fig. 8 

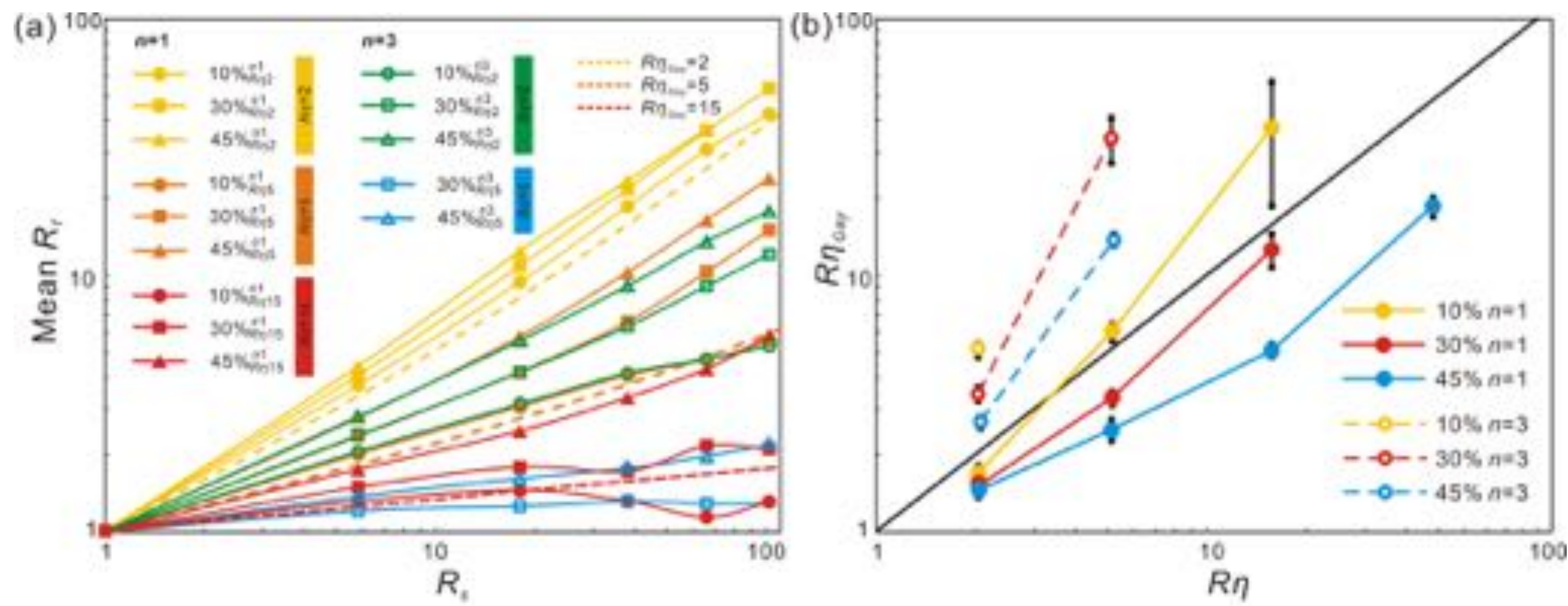

Fig. 9 

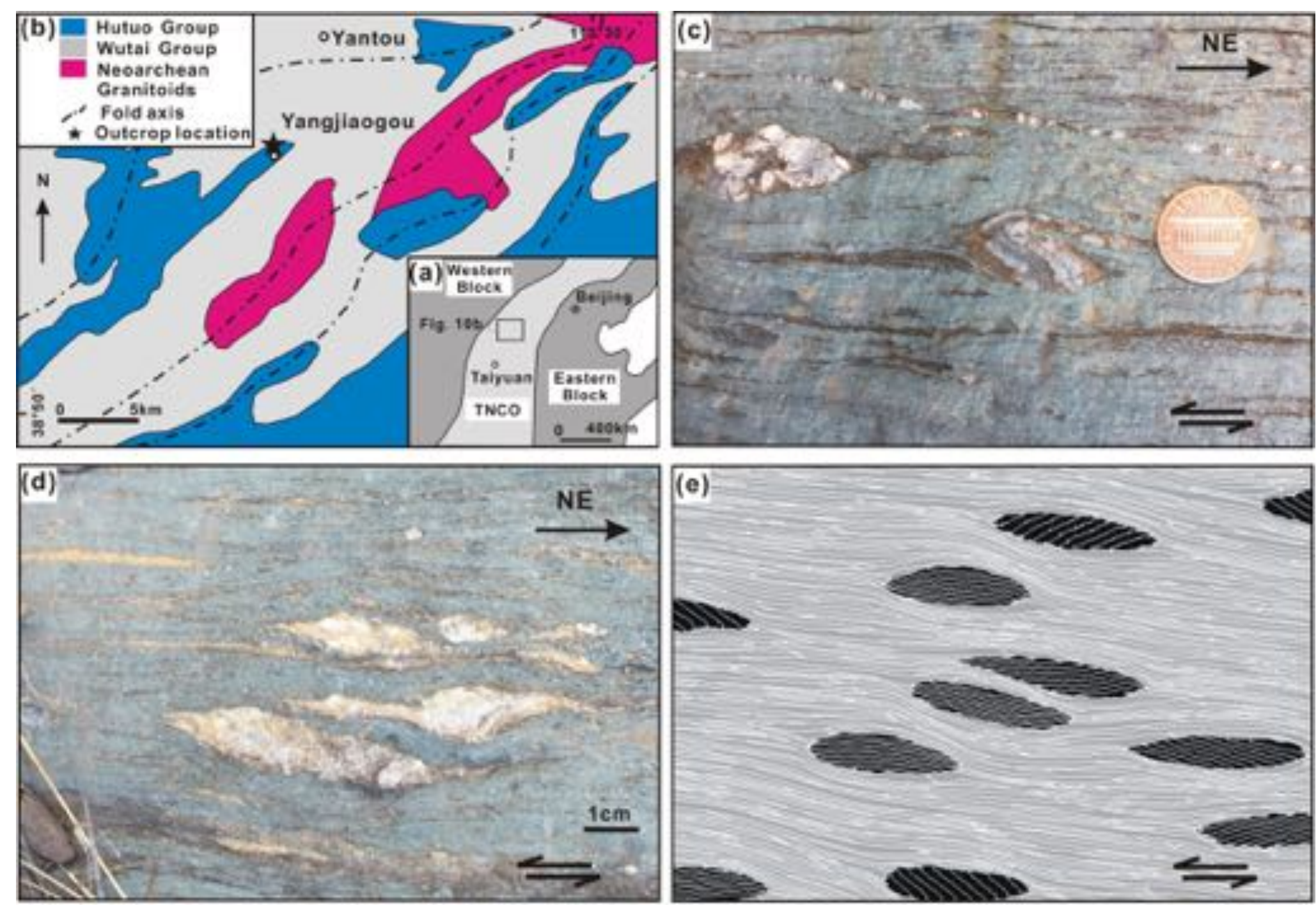

Fig. 10 


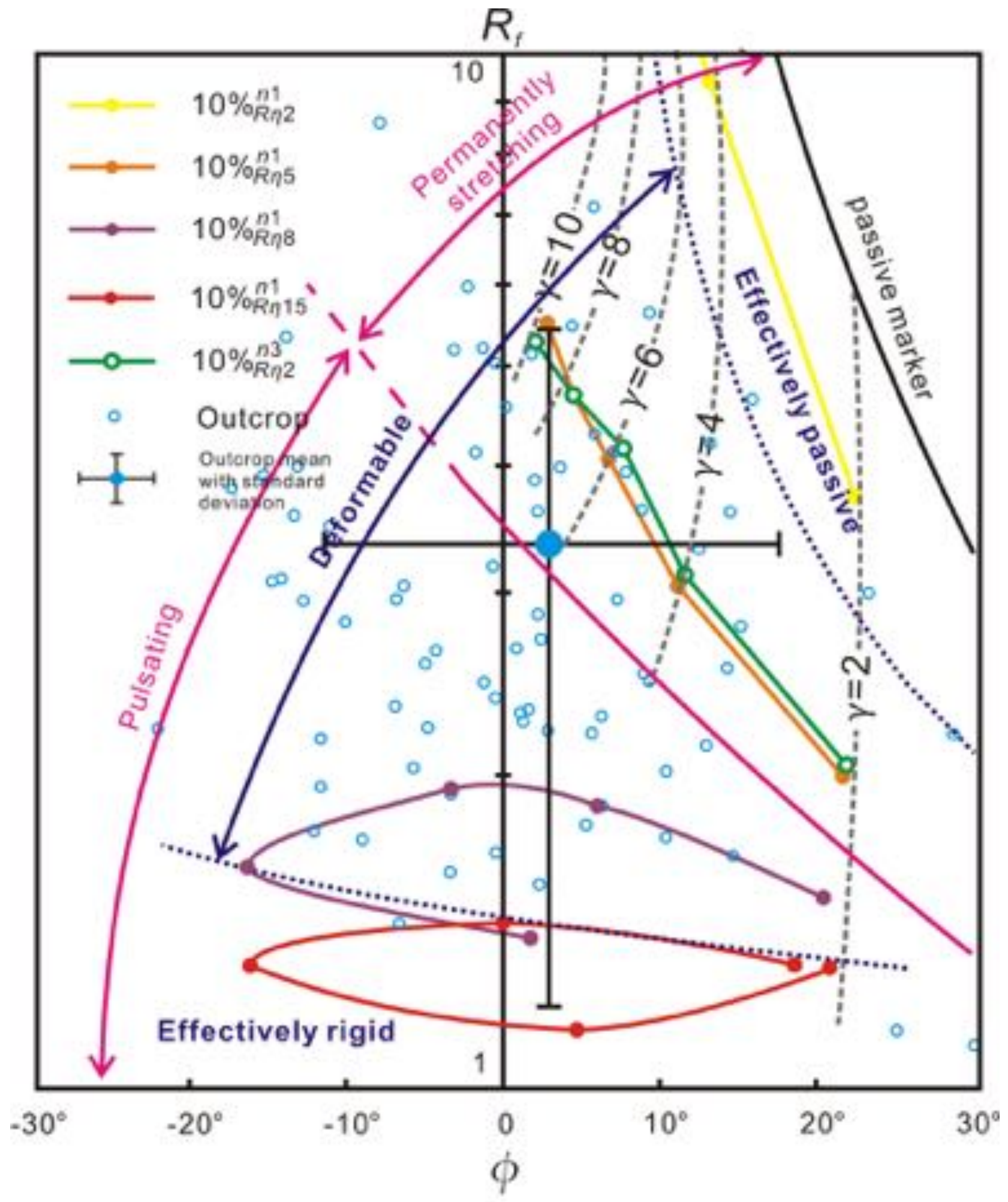

Fig. 11 